\title{
Gas Test Loop Facilities Alternatives Assessment Report
}

\author{
William F. Skerjanc \\ Glen R. Longhurst
}

July 2005

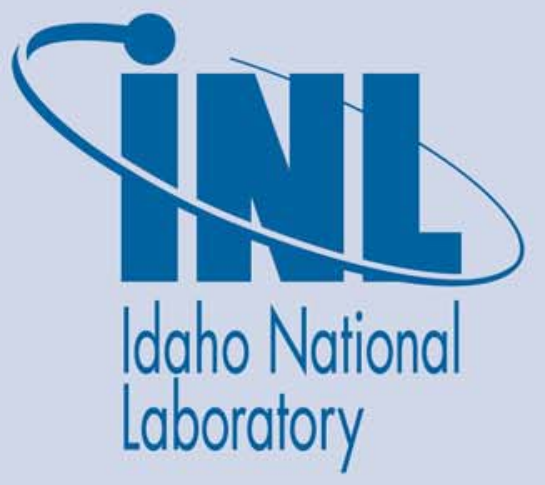

The INL is a U.S. Department of Energy National Laboratory operated by Battelle Energy Alliance 
INL/EXT-05-00263

Rev. 1

\section{Gas Test Loop Facilities Alternatives Assessment Report}

William F. Skerjanc

Glen R. Longhurst

July 2005

Idaho National Laboratory

Fission and Fusion Systems Department

Idaho Falls, Idaho 83415-3860

Prepared for the

U.S. Department of Energy

Assistant Secretary for Nuclear Energy

Under DOE Idaho Operations Office

Contract DE-AC07-05ID14517 


\section{Gas Test Loop Facilities Alternatives Assessment Report}

INL/EXT-05-00263

Rev. 1

July 2005

Approved by:
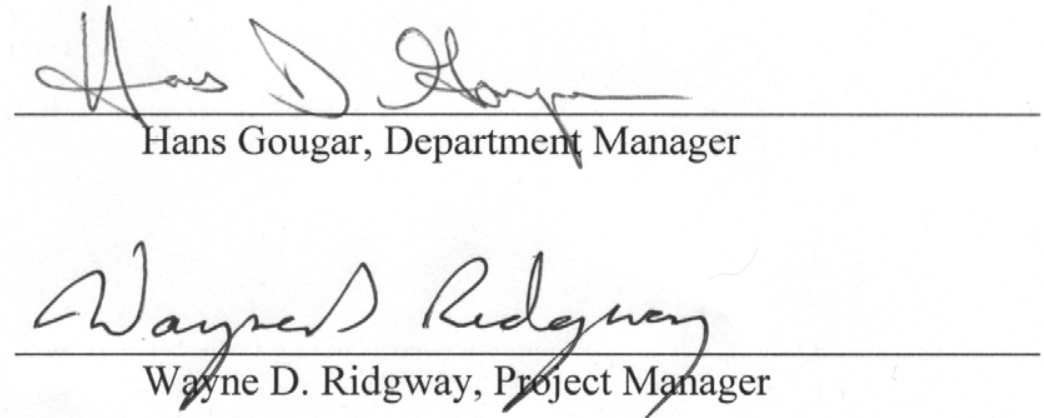

Willean F. Sann

William F. Skerjanc

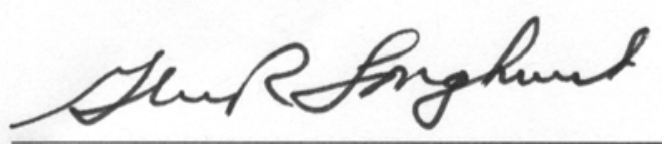

Glen R. Longhurst

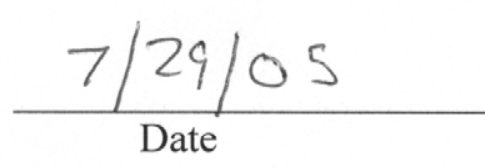

$\frac{7 / 29 / 05}{\text { Date }}$

$7 / 28 / 05$

Date

$7 / 28 / 05$

Date 


\begin{abstract}
An important task in the Gas Test Loop (GTL) conceptual design was to determine the best facility to serve as host for this apparatus, which will allow fast-flux neutron testing in an existing nuclear facility. A survey was undertaken of domestic and foreign nuclear reactors and accelerator facilities to arrive at that determination. Two major research reactors in the U.S. were considered in detail, the Advanced Test Reactor (ATR) and the High Flux Isotope Reactor (HFIR), each with sufficient power to attain the required neutron fluxes. HFIR routinely operates near its design power limit of $100 \mathrm{MW}$. ATR has traditionally operated at less than half its design power limit of $250 \mathrm{MW}$. Both of these reactors should be available for at least the next 30 years. The other major U.S. research reactor, the Missouri University Research Reactor, does not have sufficient power to reach the required neutron flux nor do the smaller research reactors. Of the foreign reactors investigated, BOR-60 is perhaps the most attractive. Monju and BN-600 are power reactors for their respective electrical grids. Although the Joyo reactor is vigorously campaigning for customers, local laws regarding transport of radioactive material mean it would be very difficult to retrieve test articles from either Japanese reactor for post irradiation examination. PHENIX is scheduled to close in 2008 and is fully booked until then. FBTR is limited to domestic (Indian) users only. Data quality is often suspect in Russia. The only accelerator seriously considered was the Material Test Station (MTS) currently proposed for operation at Los Alamos National Laboratory. The neutron spectrum in MTS is similar to that found in a fast reactor, but it has a pronounced high-energy tail that is atypical of fast fission reactor spectra. First irradiation in the MTS is being contemplated for midway through 2010. Detailed review of these facilities resulted in the recommendation that the ATR would be the best host for the GTL.
\end{abstract}




\section{CONTENTS}

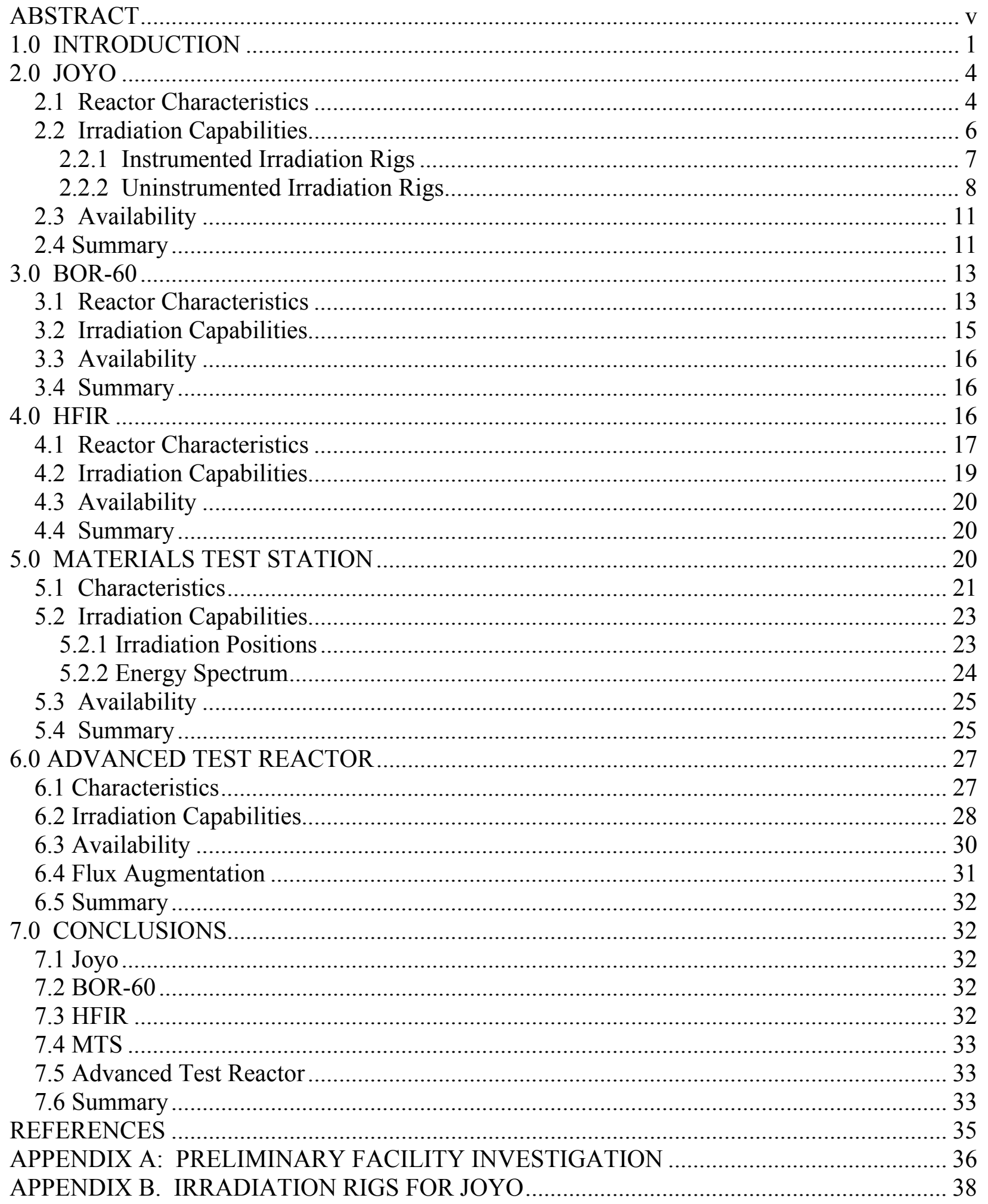




\section{ACRONYMS}

$\begin{array}{ll}\text { AFCI } & \text { Advanced Fuel Cycle Initiative } \\ \text { ATR } & \text { Advanced Test Reactor } \\ \text { EXIR } & \text { ex-vessel irradiation rig } \\ \text { MTS } & \text { Fuels and Materials Test Station, Los Alamos } \\ \text { Gen IV } & \text { Generation IV Reactor Program } \\ \text { GTL } & \text { Gas Test Loop Program } \\ \text { HFIR } & \text { High Flux Isotope Reactor } \\ \text { ILC } & \text { independent lead-cooled channel } \\ \text { INTA } & \text { instrumented test assembly } \\ \text { LANL } & \text { Los Alamos National Laboratory } \\ \text { LANSCE } & \text { Los Alamos Neutron Science Center } \\ \text { MARICO } & \text { material testing rig with high temperature control } \\ \text { NW } & \text { northwest } \\ \text { ORNL } & \text { Oak Ridge National Laboratory } \\ \text { RB } & \text { removable beryllium } \\ \text { UNIS } & \text { uninstrumented test assembly } \\ \text { UPR } & \text { upper core structure irradiation plug rig }\end{array}$

\section{FIGURES}

Figure 1. MK-III core layout of Joyo.....................................................................

Figure 2. Fast Flux distribution throughout core as a function of hexagonal ring

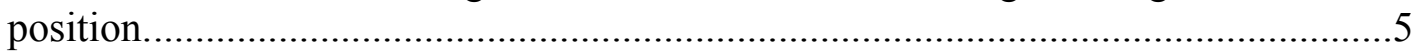

Figure 3. Testing Capabilities for Joyo. ......................................................................

Figure 4. Availability of in core irradiation facilities in Joyo...........................................11

Figure 5. BOR-60 core layout (1,2,3 - fuel, blanket assemblies, and control rods, respectively; 4 - vertical experimental channel; 5 - instrumented channel for irradiation; 6 - cells with $\mathrm{ZrH}_{2}$ assemblies).....................................................13

Figure 6. Cross section of the ILC in heat exchanger zone (dimensions in $\mathrm{mm}$ ).................15

Figure 7. Sectional plan view of the HFIR core .......................................................... 17

Figure 8. Typical radial neutron flux distributions at core horizontal midplane with

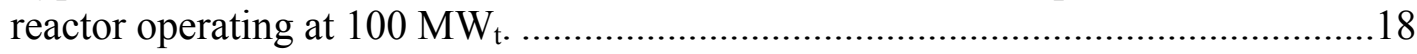

Figure 9. Hydraulic tube capsule assembly ...............................................................19

Figure 10. Target loading in flux trap ( 1 to 7 and $\mathrm{A}$ to $\mathrm{G}$ indicate rows).............................20

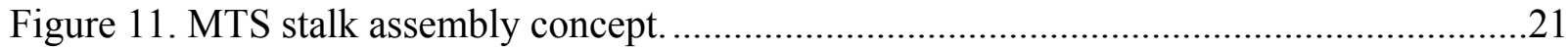

Figure 12. Fast neutron flux map $\left(\mathrm{E}_{\mathrm{n}}>0.1 \mathrm{MeV}\right)$ for the LBE-cooled $\mathrm{U}_{10}$ Mo target configuration in MTS.....

Figure 13. Fast neutron flux map $\left(\mathrm{E}_{\mathrm{n}}>0.1 \mathrm{MeV}\right)$ for a LBE-cooled $\mathrm{U}_{10} \mathrm{Mo} \operatorname{target}(\mathrm{z}=3.5$ to 5.5$)$. 
Figure 14. MTS irradiation facility configuration.

Figure 15. MTS lethargy flux spectrum compared to a typical fast reactor spectrum.............24

Figure 16. Comparison of neutron energy spectra. ............................................................25

Figure 17. MCNP calculation results for water-cooled tungsten targets in MTS for a 1$\mathrm{mA}$ proton beam at (a) $800 \mathrm{MeV}$, and (b) $3 \mathrm{GeV}$ beam energy. ..........................26

Figure 18. Basic configuration of the ATR core showing irradiation positions. ......................28

Figure 19. Unperturbed five-energy-group neutron flux intensity profiles over the active core length of the ITV in the ATR center flux trap for total reactor power of $125 \mathrm{MW}$ th.

\section{TABLES}

Table 1. Comparison of Candidate Alternative Irradiation Facilities to the Required Technical and Functional Requirements of the Proposed ATR GTL.

Table 2. Comparison of Candidate Alternative Irradiation Facilities to the Desired Technical and Functional Requirements of the Proposed GTL. ..................................

Table 3. Peak Fast Flux and Peak Fast Fluence in Joyo [] .....................................................5

Table 4. Specifications and Operating Conditions for Joyo [] ..............................................6

Table 5. Irradiation Tests in Joyo and Specified Accuracy for Neutron Fluence []....................7

Table 6. Features and Testing Capabilities for the Instrumented Test Assemblies [2]...............9

Table 7. Features and Testing Capabilities for the Uninstrumented Test Assemblies [2].........10

Table 8. Comparison of Irradiation Rigs compared to Gas Test Loop Requirements. ...............12

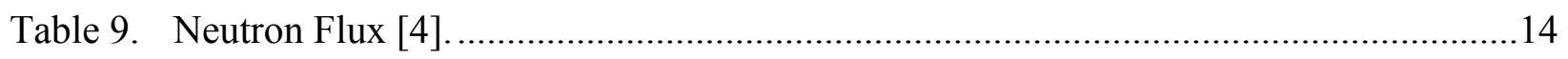

Table 10. Specifications and Operating Conditions for BOR-60 [5] ......................................14

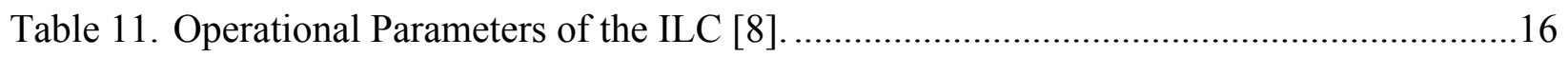

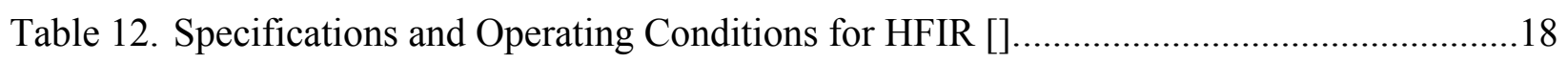

Table 13. Comparison of the $\mathrm{W} / \mathrm{H}_{2} \mathrm{O}$ and $\mathrm{U} / \mathrm{LBE}$ Options [12] ............................................23

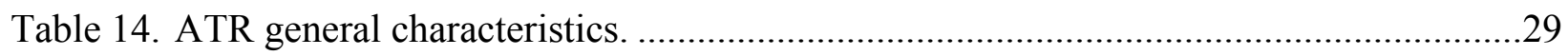

Table 15. Approximate peak flux values for various ATR capsule positions for a reactor power of $110 \mathrm{MW}_{\text {th }}\left(22 \mathrm{MW}_{\text {th }}\right.$ in each lobe $)$. 


\subsection{INTRODUCTION}

Fast neutron irradiation facilities have been investigated to determine if there are viable alternatives for the proposed Gas Test Loop (GTL) for performing materials testing that supports the needs of U.S. nuclear programs. From a preliminary assessment of domestic research reactors, foreign fast reactors, and domestic accelerator driven systems, five facilities have emerged as candidates worthy of further investigation (see Appendix A). These facilities are the foreign fast reactors Joyo and BOR-60, the domestic thermal High Flux Isotope Reactor (HFIR), the Advanced Test Reactor (ATR), and the proposed domestic accelerator driven Materials Test Station (MTS).

Other candidate facilities were identified but eliminated from further consideration based on the fundamental testing requirements and on issues of access and priority. PHENIX is a fast reactor at Cadarache in France that has operated for many years. While it is an excellent research facility, it is scheduled to close in 2008 and will not be available. BN-600 in Russia and Monju in Japan were also considered. Both of these are commercial power reactors in which research would be difficult and priority would be lacking. The Fast Breeder Test Reactor (FBTR) in India has a fast flux capability, but its use is limited to domestic (Indian) users only. Therefore it could not be considered as a potential site for the GTL.

The Joyo reactor is located in Japan and operated by the Japan Nuclear Cycle Development Institute. It is a sodium cooled fast reactor that has been operated since 1977. The BOR-60 fast reactor is located in Russia. It also uses sodium as primary coolant. BOR-60 has completed many successful irradiation campaigns since it began operating in 1969. Oak Ridge National Laboratory (ORNL) in Tennessee operates the HFIR. It is considered one of the most powerful thermal research reactors in the world. The Advanced Test Reactor (ATR) at the Idaho National Laboratory has the highest power of any remaining test reactor in the western hemisphere, and it has the largest test space volumes available in any existing reactor. The proposed MTS will utilize the existing Los Alamos Neutron Science Center (LANSCE) linear accelerator and is being planned for specific use in fuel and material irradiation campaigns. The first irradiation campaign in MTS is scheduled to begin in fiscal year 2010.

Candidate irradiation test facilities have been evaluated with respect to the required and desired capabilities specified in the Gas Test Loop Technical and Functional Requirements (T\&FR) [1] for the operation of the gas test loop. Highest priority was placed on facilities that are capable of producing a fast neutron flux density $\left(E_{n}>0.1 \mathrm{MeV}\right)$ of $10^{15} \mathrm{n} / \mathrm{cm}^{2} / \mathrm{s}$, of operating in an environment with a fast-to-thermal flux ratio greater than 15, and of accommodating test samples with a diameter of $2.54 \mathrm{~cm}$ and a length of $15.5 \mathrm{~cm}$. Other important factors that were considered when comparing the irradiation facilities with the ATR gas test loop were availability and cost.

Table 1 summarizes the capabilities of the major candidate facilities and compares them to the required technical and functional requirements for the proposed gas test loop. Table 2 compares these facilities to the desired technical and functional requirements for the proposed gas test loop. 


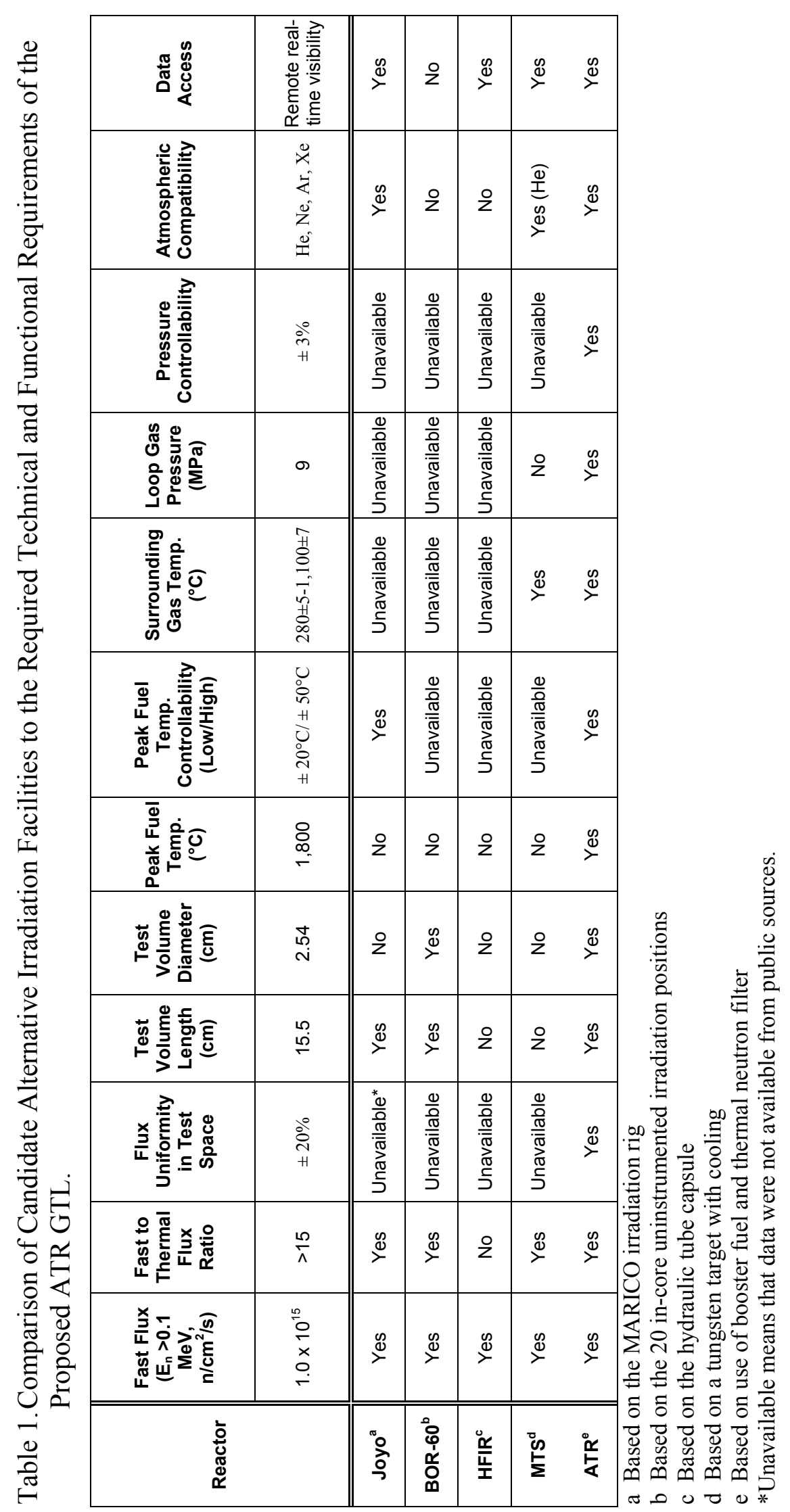




\begin{tabular}{|c|c|c|c|c|c|c|c|c|}
\hline$\underset{⿱ 乛}{ \pm}$ & 焉 & 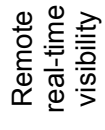 & $\stackrel{\infty}{\succ}$ & zo & $\stackrel{\infty}{\succ}$ & $\stackrel{\infty}{\succ}$ & $\stackrel{\infty}{\check{\infty}}$ & \\
\hline 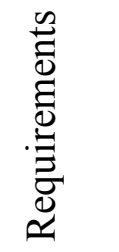 & 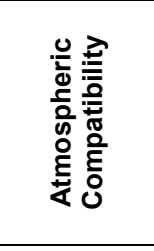 & 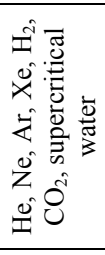 & 으 & $\stackrel{\circ}{z}$ & 2o & $\begin{array}{l}\frac{0}{1} \\
\substack{1 \\
0 \\
\nu}\end{array}$ & 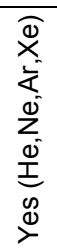 & \\
\hline 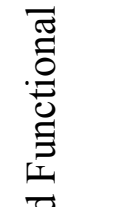 & 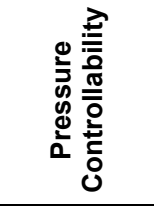 & $\frac{\stackrel{\circ}{+}}{H}$ & $\begin{array}{l}\frac{0}{0} \\
\frac{\pi}{0} \\
\frac{\pi}{\bar{\pi}} \\
\frac{\pi}{0} \\
\frac{5}{5}\end{array}$ & 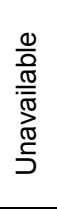 & 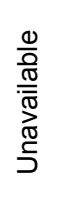 & $\begin{array}{l}\frac{0}{0} \\
\frac{0}{0} \\
\frac{0}{\pi / 0} \\
\frac{\pi}{5} \\
\frac{5}{5}\end{array}$ & $\stackrel{\infty}{\succ}$ & \\
\hline 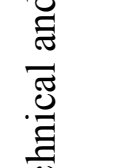 & 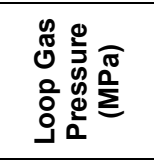 & $\stackrel{2}{N}$ & $\begin{array}{l}\frac{0}{0} \\
\frac{0}{0} \\
\frac{0}{\pi} \\
\frac{\pi}{0} \\
\stackrel{5}{5} \\
\end{array}$ & $\begin{array}{l}\frac{0}{0} \\
\frac{0}{0} \\
\frac{0}{\pi} \\
\frac{\pi}{0} \\
\frac{0}{5} \\
\end{array}$ & $\begin{array}{l}\frac{0}{0} \\
\frac{0}{0} \\
\frac{0}{\pi} \\
\frac{\pi}{\pi} \\
\stackrel{0}{5} \\
\end{array}$ & $\begin{array}{l}\frac{0}{0} \\
\frac{0}{0} \\
\frac{0}{\pi / 0} \\
\frac{\pi}{0} \\
\frac{5}{5} \\
\end{array}$ & zo & \\
\hline 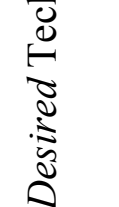 & 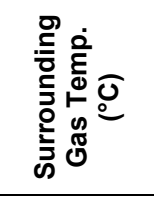 & 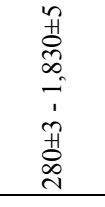 & $\begin{array}{l}\frac{0}{0} \\
\frac{0}{0} \\
\frac{0}{\bar{T}} \\
\frac{\pi}{0} \\
\frac{0}{5}\end{array}$ & $\begin{array}{l}\frac{0}{0} \\
\frac{0}{0} \\
\frac{0}{\pi} \\
\frac{\pi}{0} \\
\frac{0}{5}\end{array}$ & $\begin{array}{l}\frac{0}{0} \\
\frac{0}{0} \\
\frac{0}{\bar{N}} \\
\frac{\pi}{0} \\
\stackrel{5}{J}\end{array}$ & $\stackrel{\infty}{\stackrel{\infty}{\nu}}$ & $\stackrel{\infty}{\infty}$ & \\
\hline 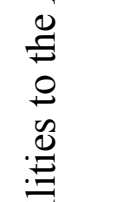 & 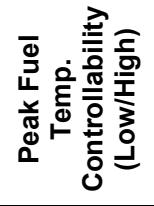 & $\begin{array}{l}0 \\
0 \\
0 \\
+1 \\
+1 \\
0 \\
i \\
i \\
+1\end{array}$ & $\stackrel{\infty}{\nu}$ & $\begin{array}{l}\frac{0}{0} \\
\frac{0}{0} \\
\frac{0}{\pi} \\
\frac{\pi}{0} \\
\stackrel{0}{J}\end{array}$ & $\begin{array}{l}\frac{0}{0} \\
\frac{0}{0} \\
\frac{\pi}{\overline{0}} \\
\frac{\pi}{0} \\
\frac{0}{5}\end{array}$ & 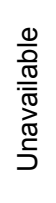 & $\stackrel{\infty}{\underset{\nu}{\infty}}$ & \\
\hline . & 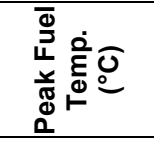 & $\begin{array}{l}8 \\
\text { m } \\
\text { m. }\end{array}$ & ㅇ & 으 & z & z) & zo & \\
\hline$\underset{\Xi}{\tilde{E}}$ & 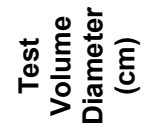 & 0 & ㅇ & $\stackrel{\mathscr{\infty}}{\succ}$ & 2o & ㅇ & $\stackrel{\infty}{\underset{\nu}{\infty}}$ & $:_{0}^{0}$ \\
\hline 茑 & 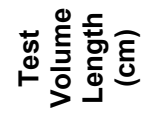 & $\overline{6}$ & zo & ㅇ & ㅇ & z) & $\stackrel{\infty}{\underset{\infty}{\infty}}$ & 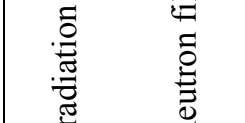 \\
\hline 苞 & 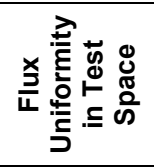 & in & 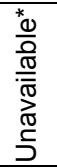 & 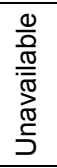 & 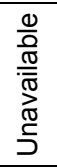 & 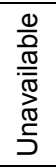 & $\stackrel{\infty}{\nu}$ & 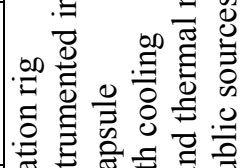 \\
\hline 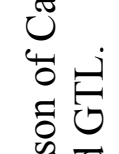 & 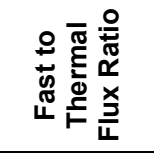 & 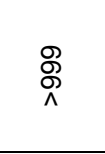 & $\stackrel{\infty}{>}$ & $\stackrel{\infty}{>}$ & ㅇ & $\begin{array}{l}\frac{0}{0} \\
\frac{0}{0} \\
\frac{010}{\bar{N}} \\
\frac{0}{0} \\
\frac{0}{5} \\
\end{array}$ & zo & 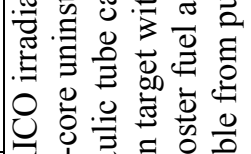 \\
\hline 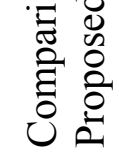 & 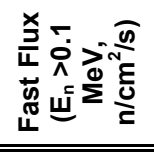 & $\begin{array}{l}\stackrel{n}{\circ} \\
\stackrel{0}{x} \\
\stackrel{2}{\circ} \\
\stackrel{m}{\infty}\end{array}$ & $\stackrel{\infty}{\rightleftharpoons}$ & $\stackrel{\infty}{\nu}$ & zo & 2o & zo & 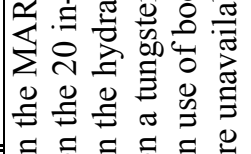 \\
\hline$\frac{i}{0}$ & 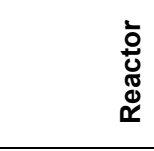 & & ْे & 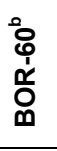 & $\frac{\stackrel{0}{\frac{\kappa}{4}}}{\frac{1}{I}}$ & $\stackrel{i n}{\stackrel{0}{E}}$ & 曼 & 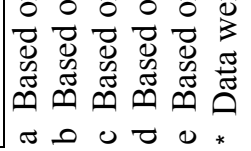 \\
\hline
\end{tabular}




\section{$2.0 \mathrm{JOYO}$}

The Joyo reactor in Japan is a 140 megawatt thermal $\left(\mathrm{MW}_{\mathrm{t}}\right)$, sodium-cooled experimental fast reactor that is used by domestic and foreign institutions. Many research and development programs have been completed in Joyo since it began operating in 1977. The results from these programs have led to new technology that has been employed in Monju, a fast reactor also located in Japan but currently shut down, and other commercialized fast reactors. The three main objectives of Joyo are [2]:

- Advancement of technology through operation and experiment

- Conducting irradiation tests on fuel and materials

- Validation of innovative technology for development of future fast reactors

\subsection{Reactor Characteristics}

In 2002, the reactor was upgraded from a MK-II core to a MK-III core to improve its irradiation capabilities and availability to customers. The core consists of a hexagonal prism and has 85 subassemblies. There are various positions throughout the core used for irradiating fuel and materials. The reactor core layout can be found in Figure 1.

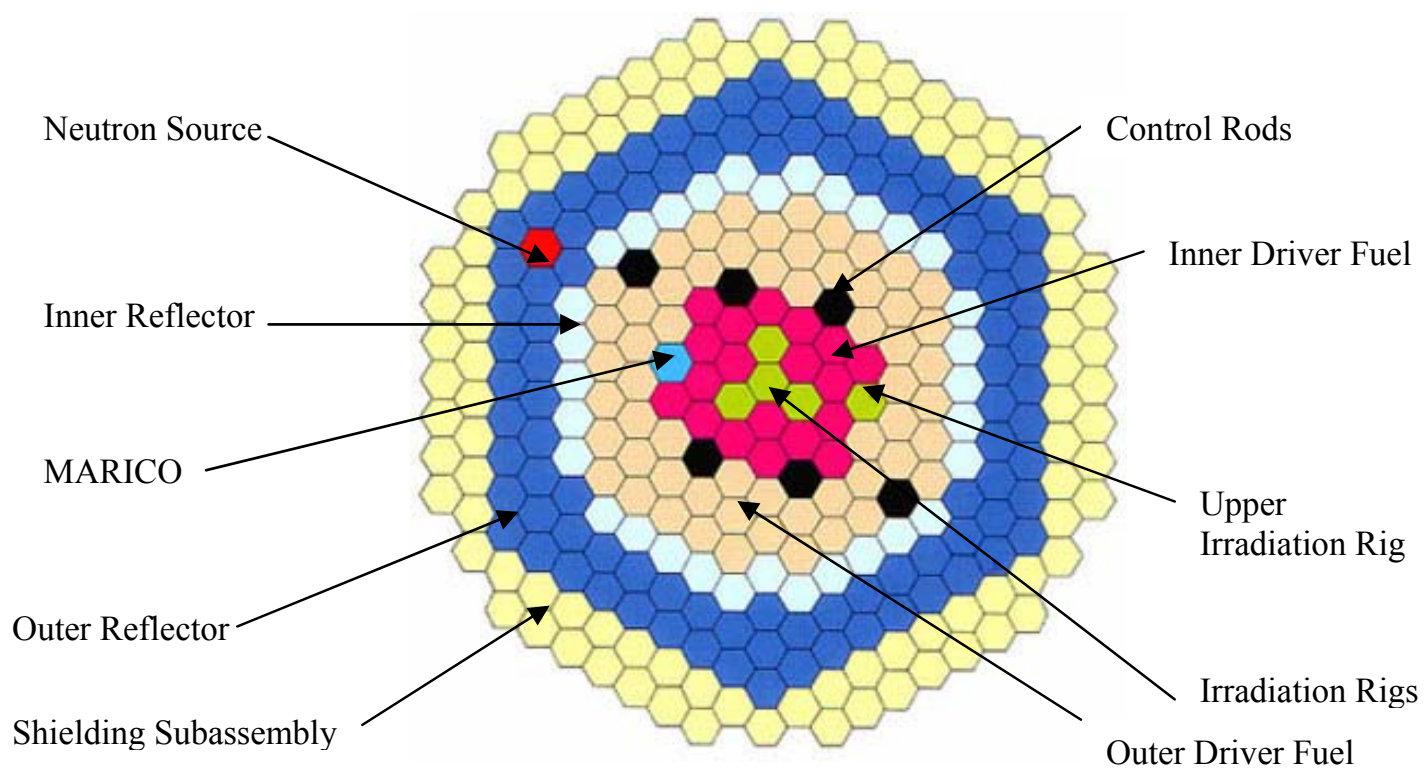

Figure 1. MK-III core layout of Joyo [3].

When operating at a maximum power level of $140 \mathrm{MW}_{\mathrm{t}}$, Joyo has a peak fast flux $\left(\mathrm{E}_{\mathrm{n}}>0.1\right.$ $\mathrm{MeV})$ of $4 \times 10^{15} \mathrm{n} / \mathrm{cm}^{2} / \mathrm{s}$. The thermal neutron flux in the reactor is relatively small $\left(3.0 \times 10^{11}\right.$ $\mathrm{n} / \mathrm{cm}^{2} / \mathrm{s}$ in the material testing rig with temperature control) resulting in a large fast-to-thermal flux ratio greater than 999 . The fast neutron flux distribution throughout the core is illustrated in Figure 2 and summarized in Table 3. With such a high fast flux, the damage rate of materials irradiated in the reactor is greater than 15 displacements per atom (dpa) per year. Fuel samples located in the core can be irradiated at very high temperatures simulating conditions expected in most fast reactor designs. The specifications and operating conditions for Joyo are shown in Table 4. 


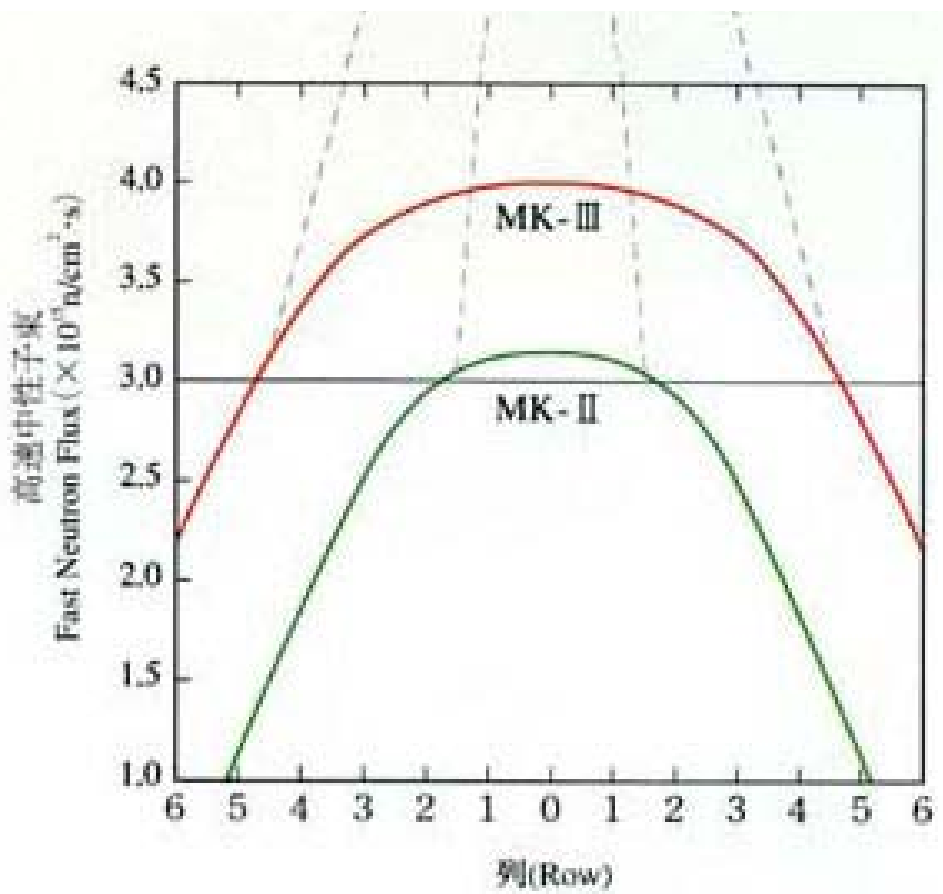

Figure 2. Fast Flux distribution throughout core as a function of hexagonal ring position [3].

Table 3. Peak Fast Flux and Peak Fast Fluence in Joyo [4].

\begin{tabular}{|c|c|c|}
\hline Reactor Core Ring & Peak Fast Flux $\left(\mathrm{n} / \mathrm{cm}^{2} / \mathrm{s}\right)$ & $\begin{array}{c}\text { Peak Fast Neutron Fluence in a 60 day } \\
\text { cycle }\left(\mathrm{n} / \mathrm{cm}^{2}\right)\end{array}$ \\
\hline 0 & $4.0 \times 10^{15}$ & $2.1 \times 10^{22}$ \\
\hline 1 & $4.0 \times 10^{15}$ & $2.1 \times 10^{22}$ \\
\hline 2 & $3.9 \times 10^{15}$ & $2.0 \times 10^{22}$ \\
\hline 3 & $3.8 \times 10^{15}$ & $2.0 \times 10^{22}$ \\
\hline 4 & $3.3 \times 10^{15}$ & $1.7 \times 10^{22}$ \\
\hline 5 & $2.8 \times 10^{15}$ & $1.5 \times 10^{22}$ \\
\hline 6 & $2.2 \times 10^{15}$ & $1.1 \times 10^{22}$ \\
\hline
\end{tabular}


Table 4. Specifications and Operating Conditions for Joyo [5].

\begin{tabular}{|l|l|}
\hline Type & Fast Reactor, test \\
\hline Location & Oarai Engineering Center of JNC, Japan \\
\hline Operator & Japan Nuclear Cycle Development Institute \\
\hline Annual Operating Cost & $\$ 54.2$ M (U.S.) \\
\hline Date of First Criticality & 1977 (MK-I) \\
& 1982 (MK-II) \\
\hline Thermal Power Output & 2003 (MK-III) \\
\hline Electrical Power Output & $140 \mathrm{MW}$ \\
\hline Core & N/A \\
Geometry & \\
Equivalent Diameter & Hexagonal Prism \\
Height & $0.80 \mathrm{~m}$ \\
Core Volume & $0.50 \mathrm{~m}$ \\
Number of Subassemblies & 251 liters \\
Fuel Pins per Subassembly & 85 \\
Max Fast Flux (E $>0.1 \mathrm{MeV})$ & 127 \\
\hline Coolant & $4.0 \mathrm{x} 10^{15} \mathrm{n} / \mathrm{cm}^{2} / \mathrm{s}$ \\
Inlet Temperature & $\mathrm{Liquid} \mathrm{Sodium}$ \\
Outlet Temperature & $350^{\circ} \mathrm{C}$ \\
Cooling Configuration & $500^{\circ} \mathrm{C}$ \\
Number of Loops & Loops \\
Flow Rate per Loop & 2 \\
\hline Fuel & $375 \mathrm{~kg} / \mathrm{s}$ \\
Enrichment & PuO ${ }_{2}-\mathrm{UO} \mathrm{O}_{2} \mathrm{Blankets}$ \\
Max Cladding Temperature & $18 \%{ }^{235} \mathrm{U}, 16 \%$ Pu Inner, $21 \%$ Pu Outer \\
Max Fuel Temperature & $670^{\circ} \mathrm{C}$ \\
\hline Operation Cycle & $2530^{\circ} \mathrm{C}$ \\
Reactor Running & \\
Refueling & $60 \mathrm{days}$ \\
\hline Test Positions in Core & 15 days \\
\hline Plant Availability Factor & 21 \\
\hline
\end{tabular}

\subsection{Irradiation Capabilities}

There are 21 in-core testing positions available in Joyo that allow for the simultaneous irradiation of 11 possible irradiation rigs. Four of these rigs are instrumented and can be used to collect and monitor real-time irradiation data of fuels and materials. The remaining seven rigs are uninstrumented and can be used for various irradiation tests of both fuels and materials. Irradiation testing capabilities for Joyo are categorized in Figure 3. The accuracy of the neutron fluence for irradiation tests is provided in Table 5. 


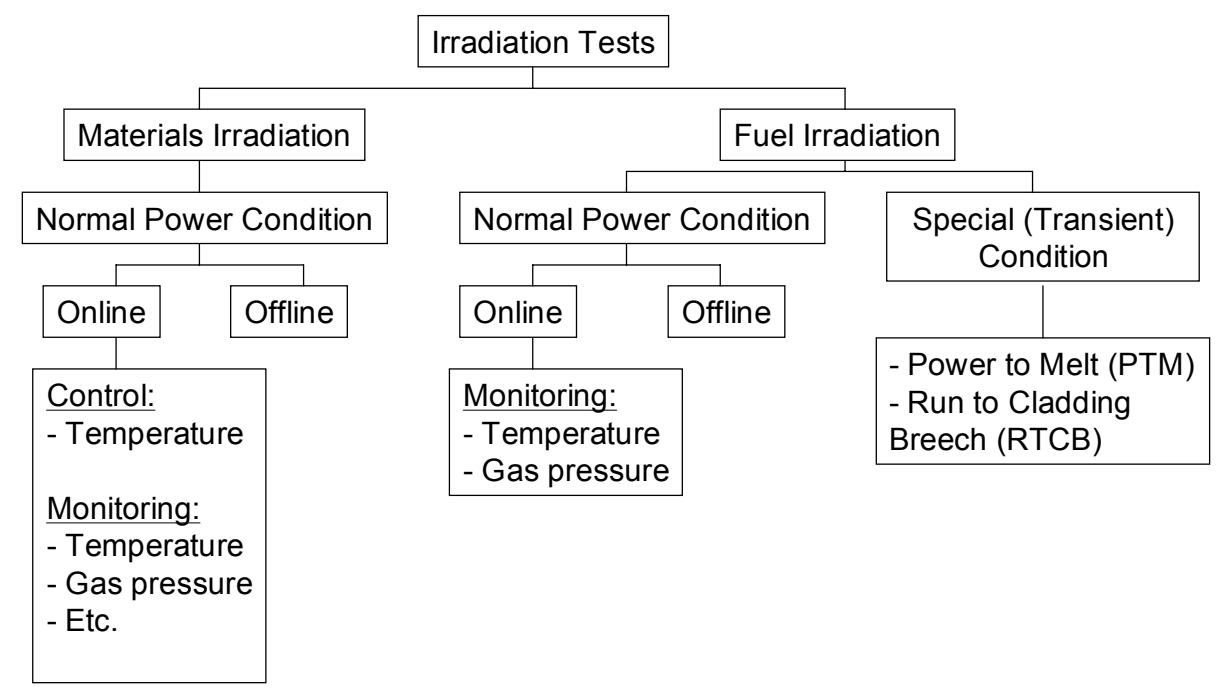

Figure 3. Testing Capabilities for Joyo [4].

Table 5. Irradiation Tests in Joyo and Specified Accuracy for Neutron Fluence [6].

\begin{tabular}{|l|l|l|l|}
\hline \multicolumn{1}{|c|}{ Test } & \multicolumn{1}{|c|}{ Purpose } & \multicolumn{1}{c|}{ Characteristics } & \multicolumn{1}{c|}{ Fluence Accuracy } \\
\hline Fuel Irradiation & $\begin{array}{l}\text { High power and } \\
\text { burnup fuels } \\
\text { development }\end{array}$ & $\begin{array}{l}\text { Linear heat rate } \\
\text { burnup }\end{array}$ & $5 \%$ for total \\
\hline $\begin{array}{l}\text { Cladding and } \\
\text { Component Material } \\
\text { Irradiation }\end{array}$ & $\begin{array}{l}\text { Low swelling and } \\
\text { high creep strength } \\
\text { materials } \\
\text { development }\end{array}$ & $\begin{array}{l}\text { dpa } \\
\text { He production }\end{array}$ & $\begin{array}{l}5-10 \% \text { for } \mathrm{E}_{\mathrm{n}}>0.1 \\
\mathrm{MeV} \text { and } 20 \% \text { for } \\
\mathrm{E}_{\mathrm{n}}>0.4 \mathrm{eV}\end{array}$ \\
\hline Surveillance & $\begin{array}{l}\text { Life evaluation of } \\
\text { reactor component }\end{array}$ & $\begin{array}{l}\text { dpa } \\
\text { He production }\end{array}$ & $\begin{array}{l}10 \% \text { for } \mathrm{E}_{\mathrm{n}}>0.1 \\
\mathrm{MeV} \text { and } 50 \% \text { for } \\
\mathrm{E}_{\mathrm{n}}>0.4 \mathrm{eV}\end{array}$ \\
\hline
\end{tabular}

\subsubsection{Instrumented Irradiation Rigs}

The instrumented test assembly (INTA) rig has been developed to obtain real-time temperature, fission product gas pressure, and flow rate data of fuels being irradiated. With a thermal output of $100 \mathrm{MW}_{\mathrm{t}}$ in the $\mathrm{MK}$ II core, the fuel could be irradiated at $1,700^{\circ} \mathrm{C}$ and is expected to be higher in the MK III core since it operates at $140 \mathrm{MW}_{\mathrm{t}}$. Information regarding the maximum size or quantity of irradiation samples that can be loaded into INTA and the fast flux are unavailable.

The upper core structure irradiation plug rig (UPR) is used primarily to obtain real-time irradiation data similar to INTA from materials that are exposed to thermal neutrons. The fast neutron flux in UPR is $6.4 \times 10^{10} \mathrm{n} / \mathrm{cm}^{2} / \mathrm{s}$ and the thermal flux is $1.8 \times 10^{9} \mathrm{n} / \mathrm{cm}^{2} / \mathrm{s}$. Temperatures 
of test specimens can be maintained between $500^{\circ} \mathrm{C}$ and $700^{\circ} \mathrm{C}$ by using electric heaters. Approximately 60 test pieces can be loaded into UPR, however no information is available regarding the physical dimensions of the test samples.

The material testing rig with temperature control (MARICO) can measure swelling, creep, and rupture strength of core material such as metals and ceramics in real-time. The fast neutron flux in MARICO is approximately 2.5 to $3.0 \times 10^{15} \mathrm{n} / \mathrm{cm}^{2} / \mathrm{s}$ while the thermal flux is $3.0 \times 10^{11}$

$\mathrm{n} / \mathrm{cm}^{2} / \mathrm{s}$. The temperature in MARICO can be controlled between the ranges of $400^{\circ} \mathrm{C}$ and $700^{\circ} \mathrm{C}$ using a gas gap of argon or helium and an electric heater with an accuracy of $\pm 4^{\circ} \mathrm{C}$. The size of specimen that can be inserted into MARICO has a maximum diameter of $0.5 \mathrm{~cm}$ and length of $3.3 \mathrm{~cm}$.

An ex-vessel irradiation rig (EXIR) is also available and is located between the reactor guard vessel and reactor safety vessel. Because it is located outside of the core, this irradiation rig does not lower the plant capacity factor. The fast flux in the EXIR is $1 \times 10^{10} \mathrm{n} / \mathrm{cm}^{2} / \mathrm{s}$ and is used for material irradiation. Temperatures in the EXIR can be maintained between $200^{\circ} \mathrm{C}$ and $600^{\circ} \mathrm{C}$ by using an electric heater. It is capable of monitoring and recording real-time irradiation data.

Table 6 lists the key features and testing capabilities of the instrumented test assemblies. Appendix B consists of figures of the instrumented irradiation rigs available for use at Joyo.

\subsubsection{Uninstrumented Irradiation Rigs}

There are four uninstrumented test assemblies (UNIS) that can also be irradiated in the inner core. The UNIS-A rig, which contains both fuel pins for sample loading and driver fuel pins, is used for high linear power irradiation testing. The UNIS-B rig contains six compartments with five fuel pins and is used in high burnup continuous tests. Coolant flow rate in each compartment can be maintained separately and interim examinations can be performed. The UNIS-C rig is used to obtain irradiation data for the behavior of fuel pin bundles under irradiation. It is capable of irradiating variable pin bundle diameters and is primarily used in verification tests of fuel subassemblies for the Monju and other demonstration fast reactors. The UNIS-D rig is similar to the UNIS-B rig, but contains 18 compartments with only one fuel pin. It also has a higher testing efficiency. Appendix B contains figures of the uninstrumented irradiation rigs A, B, and C.

A material irradiation rig (MIR) has three separate designs to irradiate core materials, absorber materials, and structural materials. All three designs are similar to UNIS-B rig. These three designs are capable of holding encapsulated materials of various sizes but information is not available regarding the maximum size of test specimens that can be accommodated in these rigs. Table 7 lists the key features and testing capabilities of the uninstrumented test assemblies. 
Table 6. Features and Testing Capabilities for the Instrumented Test Assemblies [2].

\begin{tabular}{|c|c|c|c|}
\hline & Type & Features & Tests \\
\hline $\begin{array}{l}\frac{2}{2} \\
\vec{I}\end{array}$ & INTA & $\begin{array}{l}\text { - Real-time irradiation data } \\
\text { - Equipped with thermocouples, } \\
\text { pressure monitor, and flow meters }\end{array}$ & - Fuel pins \\
\hline \multirow{3}{*}{ 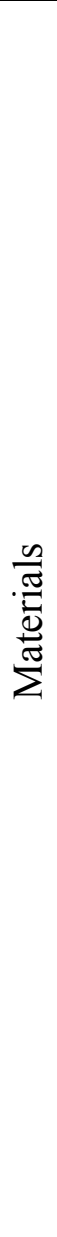 } & UPR & $\begin{array}{l}\text { - Located in upper core structure } \\
\text { - Fast flux } \sim 6.4 \times 10^{10} \mathrm{n} / \mathrm{cm}^{2} / \mathrm{s} \\
\text { - Thermal flux } \sim 1.8 \times 10^{9} \mathrm{n} / \mathrm{cm}^{2} / \mathrm{s} \\
\text { - } 500^{\circ} \mathrm{C} \text { to } 700^{\circ} \mathrm{C} \text { temperature range } \\
\text { controlled with electrical heaters } \\
\text { - Holds up to } 60 \text { test specimens }\end{array}$ & $\begin{array}{l}\text { Irradiation data on } \\
\text { reactor structural } \\
\text { materials exposed to } \\
\text { thermal neutrons } \\
\text { - Continuous } \\
\text { monitoring of } \\
\text { irradiation data }\end{array}$ \\
\hline & EXIR & $\begin{array}{l}\text { - Can be regulated between } 200^{\circ} \mathrm{C} \text { to } \\
600^{\circ} \mathrm{C} \text { by electric heaters } \\
\text { - Does not jeopardize plant capacity } \\
\text { factor } \\
\text { - Fast flux } \sim 10^{10} \mathrm{n} / \mathrm{cm}^{2} / \mathrm{s} \\
\text { - Thermal flux } \sim 5 \times 10^{10} \mathrm{n} / \mathrm{cm}^{2} / \mathrm{s} \\
\text { - Can hold three } 2 \mathrm{~mm} \mathrm{ID} \mathrm{\times} 10 \mathrm{~mm} \text { and } \\
\text { three } 3 \mathrm{~mm} \text { ID x } 15 \mathrm{~mm} \text { test } \\
\text { specimens }\end{array}$ & $\begin{array}{l}\text { - Located between the } \\
\text { reactor guard vessel } \\
\text { and safety vessel to } \\
\text { irradiate core } \\
\text { materials } \\
\text { - Continuous } \\
\text { monitoring of } \\
\text { irradiation data }\end{array}$ \\
\hline & MARICO & $\begin{array}{l}\text { - Specimen temperatures controlled } \\
\text { with an accuracy of } \pm 4^{\circ} \mathrm{C} \text { by varying } \\
\text { the ratio of helium and argon and/or } \\
\text { electrical heaters } \\
\text { - Fast flux } \sim 3.0 \times 10^{15} \mathrm{n} / \mathrm{cm}^{2} / \mathrm{s} \\
\text { - Thermal flux } \sim 3.0 \times 10^{11} \mathrm{n} / \mathrm{cm}^{2} / \mathrm{s} \\
\text { - Can hold approximately } 100 \text { test } \\
\text { specimens with a diameter of } 5 \mathrm{~mm} \\
\text { by } 33 \mathrm{~mm}\end{array}$ & $\begin{array}{l}\text { - Obtain real-time } \\
\text { irradiation data of } \\
\text { creep, swelling, and } \\
\text { rupture strength of } \\
\text { core materials } \\
\text { - Interim examinations }\end{array}$ \\
\hline
\end{tabular}


Table 7. Features and Testing Capabilities for the Uninstrumented Test Assemblies [2].

\begin{tabular}{|c|c|c|c|}
\hline \multirow{5}{*}{$\frac{n}{9}$} & Type & Features & Tests \\
\hline & UNIS-A & $\begin{array}{l}\text { - Test pins arranged in the center and } \\
\text { driver pins around the outside } \\
\text { - High fuel inventory } \\
\text { - Reactivity not greatly affected when } \\
\text { inserted into core } \\
\text { - Grid type arrangement being } \\
\text { developed }\end{array}$ & $\begin{array}{l}\text { - High linear power } \\
\text { irradiation testing } \\
\text { - Interim examination }\end{array}$ \\
\hline & UNIS-B & $\begin{array}{l}\text { Six compartments with up to five test } \\
\text { pins per compartment } \\
\text { - Coolant flow rate in each } \\
\text { compartment controlled separately }\end{array}$ & $\begin{array}{l}\text { - } \text { Parametric tests } \\
\text { - Continuous tests } \\
\text { aimed at high burnup } \\
\text { data with interim } \\
\text { examinations } \\
\end{array}$ \\
\hline & UNIS-C & 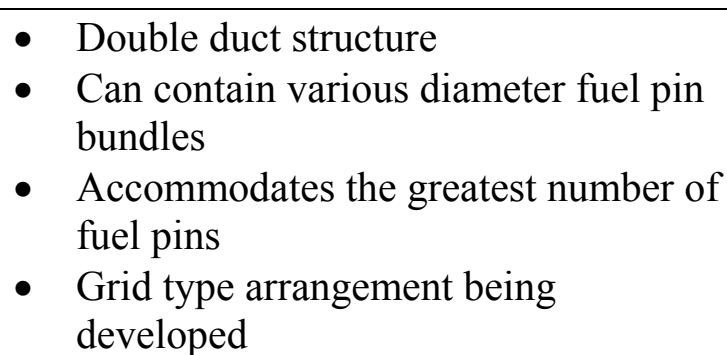 & $\begin{array}{l}\text { - Irradiation data of fuel } \\
\text { pin bundle behavior } \\
\text { - Verification tests of } \\
\text { fuel subassemblies } \\
\text { other fast reactors } \\
\text { - Interim examination }\end{array}$ \\
\hline & UNIS-D & $\begin{array}{l}\text { Eighteen compartments with one } \\
\text { irradiation test fuel pin per } \\
\text { compartment } \\
\text { - Increased efficiency of irradiation } \\
\text { tests }\end{array}$ & $\begin{array}{ll}\text { - } & \text { Parametric tests } \\
\text { - } & \text { Continuous tests } \\
\text { aimed at high burnup } \\
\text { data with interim } \\
\text { examinations } \\
\end{array}$ \\
\hline \multirow{3}{*}{ 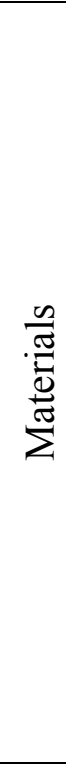 } & CMIR & $\begin{array}{ll}\text { - } & \text { Similar to UNIS-B } \\
\text { - } & \text { Specimens encapsulated and installed } \\
\text { in the compartment } \\
\text { - Temperatures are maintained with an } \\
\text { accuracy of } \pm 10^{\circ} \mathrm{C}\end{array}$ & - Core materials \\
\hline & AMIR & $\begin{array}{l}\text { - Similar to UNIS-B } \\
\text { - Specimens encapsulated and installed } \\
\text { in the compartment } \\
\text { - Temperatures are maintained with an } \\
\text { accuracy of } \pm 10^{\circ} \mathrm{C} \\
\end{array}$ & - Absorber materials \\
\hline & SMIR & $\begin{array}{l}\text { - Similar to UNIS-B } \\
\text { - Specimens encapsulated and installed } \\
\text { in the compartment } \\
\text { - Temperatures are maintained with an } \\
\text { accuracy of } \pm 10^{\circ} \mathrm{C}\end{array}$ & - $\quad$ Structural materials \\
\hline
\end{tabular}




\subsection{Availability}

Joyo typically operates for five cycles per year, each consisting of continuous operation lasting 60 days followed by shutdown for refueling. Refueling takes approximately thirteen days and twelve subassemblies are exchanged. Experiments can only be changed out while the reactor is shut down. Since upgrading to the MK-III core, Joyo has increased its plant availability factor by approximately $50 \%$. However, most of its in-core irradiation facilities are unavailable at least until 2010 as shown in Figure 4.

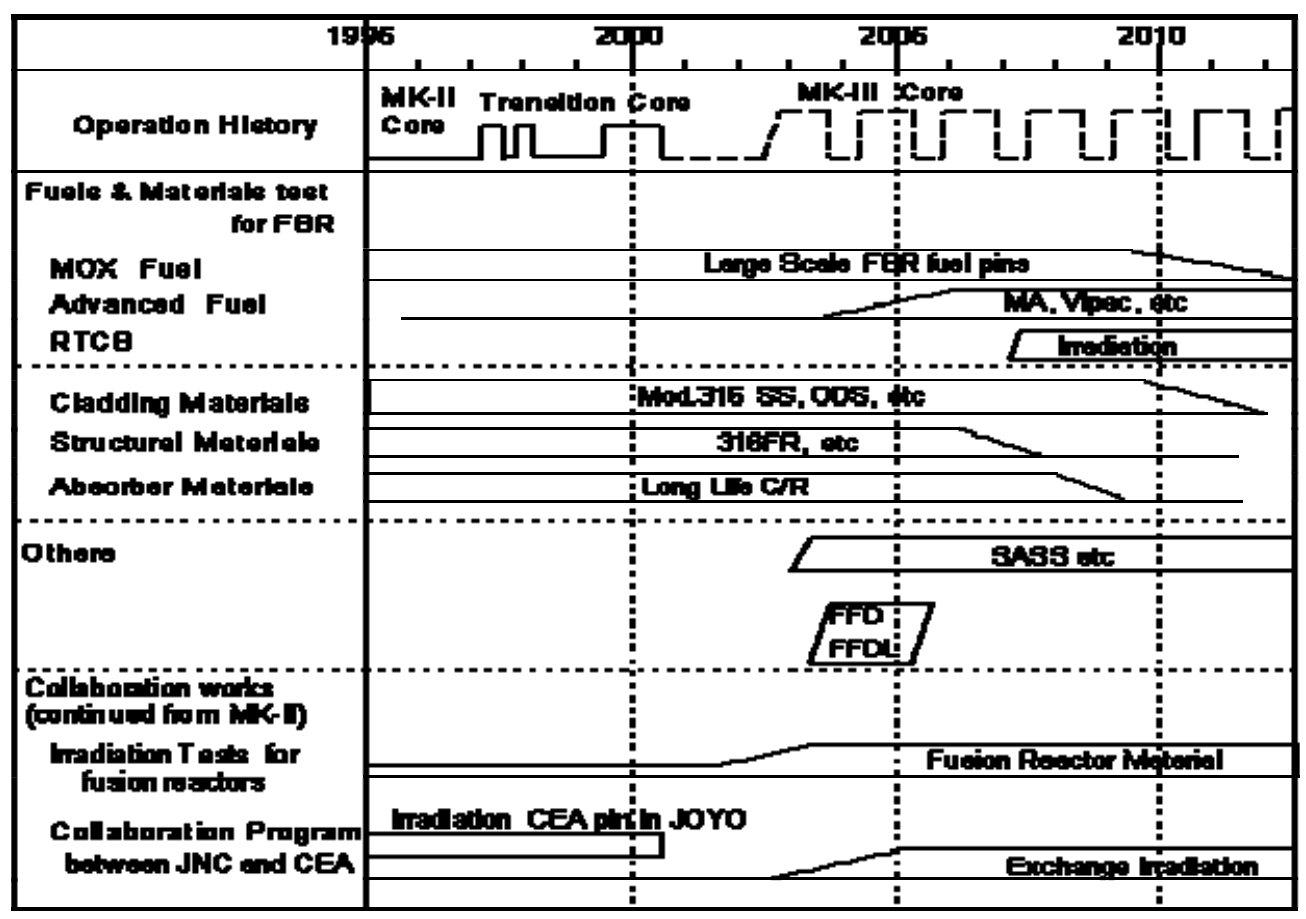

Figure 4. Availability of in core irradiation facilities in Joyo [7].

\subsection{Summary}

The irradiation rigs available in Joyo offer many advantages concerning irradiating fuels and materials. There are a variety of positions located within the core that can accommodate irradiation rigs to obtain a specified flux defined for a given irradiation test. The technology of the instrumentation associated with these irradiation rigs is well advanced and could provide real- time data similar to what is needed for the ATR gas test loop. However, it would appear that it would take several different irradiation rigs to perform all the tests needed to meet the AFCI and GEN IV objectives. Irradiation testing using these rigs could be time consuming and possibly more expensive compared to a test loop that could provide an environment capable of performing irradiation tests similar to those needed by AFCI, GEN IV, and the space nuclear programs. A comparison of these rigs relative to the technical requirements of the ATR gas test loop is given in Table 8 .

The Joyo reactor has also made significant improvements in its availability to both foreign and domestic customers, an increase of $50 \%$ from its previous core configuration. Most of its 


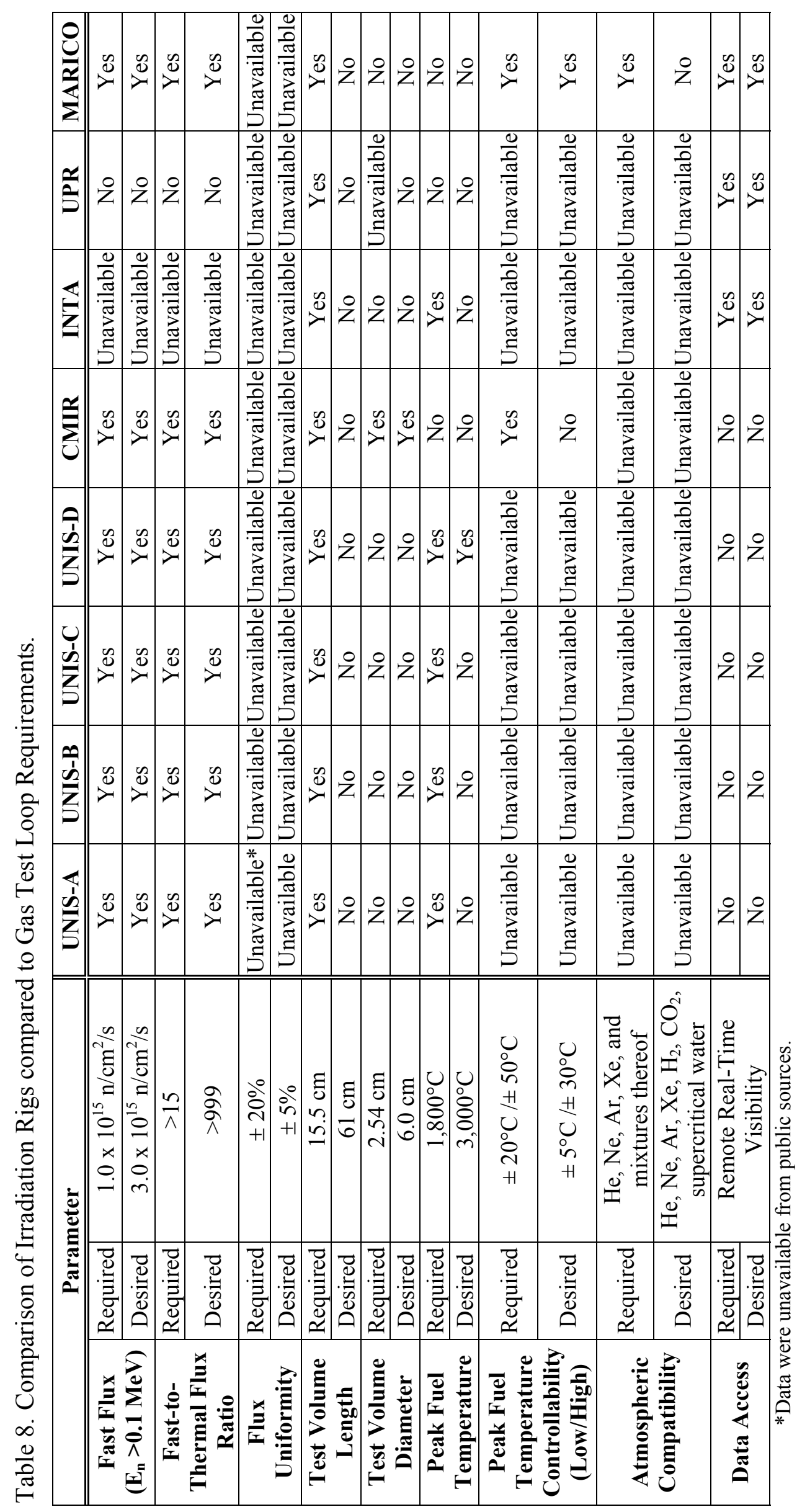


irradiation facilities, however, are fully booked until 2010 and it is unclear what the availability of the reactor will be after that. The reactor is expected to be operational for quite some time and is expected to continue fuels and material irradiations for other fast reactors.

\subsection{BOR-60}

The BOR-60 fast test reactor, located in Dimitrovgrad, Russia, is a relatively inexpensive testing facility. Many successful irradiation campaigns have been conducted at this facility since its operation began in 1969. Fuel elements and assemblies have been irradiated in BOR-60 under steady, transient, and emergency conditions. The main direction of investigation and work at the reactor include [7]:

- Testing of different neutron absorbing materials

- Radiation testing of structural reactor materials

- Testing of electro insulation, magnetic and hard melting for fusion reactors

- Investigation on radiation material science at temperatures from $330^{\circ} \mathrm{C}$ to $1,000^{\circ} \mathrm{C}$ and damage dose up to 200 dpa

- Investigation on fast reactor safety

- Investigation and testing of liquid metal technology

- Testing of experimental reactor equipment and diagnostic and safety systems

- Investigation of transmutation and incineration of long-lived radionuclides from different types of reactor spent fuel

\subsection{Reactor Characteristics}

BOR-60 has a maximum thermal output of $60 \mathrm{MW}_{\mathrm{t}}$ and produces $10 \mathrm{MW}_{\mathrm{e}}$ for the Russian electrical grid. The reactor core is a hexagonal prism comprised of 110 subassemblies. The core has an equivalent diameter of $46 \mathrm{~cm}$ and a height of $45 \mathrm{~cm}$. The core layout is shown in Figure 5 .

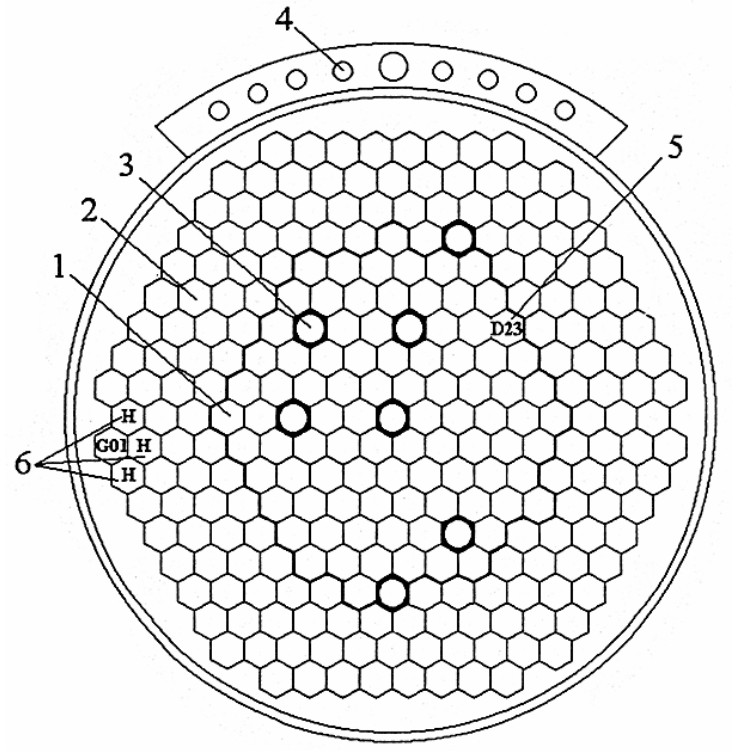

Figure 5. BOR-60 core layout (1,2,3 - fuel, blanket assemblies, and control rods, respectively; 4 - vertical experimental channel; 5 - instrumented channel for irradiation; 6 - cells with $\mathrm{ZrH}_{2}$ assemblies) [4]. 
At $60 \mathrm{MW}_{\mathrm{t}}$, the peak fast flux $\left(\mathrm{E}_{\mathrm{n}}>0.1 \mathrm{MeV}\right)$ found in the core is $3.5 \times 10^{15} \mathrm{n} / \mathrm{cm}^{2} / \mathrm{s}$. The neutron flux available in BOR-60 varies as a function of ring position from the center of the core as shown in Table 9. The reactor has a neutron fluence rate of $5 \times 10^{22} \mathrm{n} / \mathrm{cm}$ [4] per year and a damage rate of $25 \mathrm{dpa} /$ year. Large axial and radial variations in damage rate are achievable. The specifications and operating conditions for BOR-60 are shown in Table 10.

Table 9. Neutron Flux [4].

\begin{tabular}{|c|c|c|c|}
\hline Ring Position & $\begin{array}{c}\text { Thermal Flux, } \\
\mathbf{n} / \mathbf{c m}^{\mathbf{2}} / \mathbf{s}\end{array}$ & $\begin{array}{c}\text { Fast Flux }\left(\mathbf{E}_{\mathbf{n}} \mathbf{> 0 . 4}\right. \\
\mathbf{M e V}) \mathbf{n} \mathbf{\mathbf { c m }} \mathbf{\mathbf { 2 }} / \mathbf{s}\end{array}$ & $\begin{array}{c}\text { Fast-to-Thermal } \\
\text { Flux Ratio }\end{array}$ \\
\hline \hline 2 & $2.40 \times 10^{15}$ & $2.04 \times 10^{15}$ & 0.85 \\
\hline 6 & $1.95 \times 10^{15}$ & $1.10 \times 10^{15}$ & 0.56 \\
\hline
\end{tabular}

Table 10. Specifications and Operating Conditions for BOR-60 [5].

\begin{tabular}{|l|l|}
\hline Type & Fast Reactor, test \\
\hline Location & Dimitrovgrad, Russia \\
\hline Operator & Research Institute of Atomic Reactors \\
\hline Annual Operating Cost & Unavailable \\
\hline Date of First Criticality & $12 / 1 / 1969$ \\
\hline Thermal Power Output & $60 \mathrm{MW}$ \\
\hline Electrical Power Output & $10 \mathrm{MW}$ \\
\hline Core & \\
Geometry & Hexagonal Prism \\
Equivalent Diameter & $0.46 \mathrm{~m}$ \\
Height & $0.45 \mathrm{~m}$ \\
Core Volume & 75 liters \\
Number of Subassemblies & 110 \\
Fuel Pins per Subassembly & 37 \\
Max Fast Flux (E $>0.1 \mathrm{MeV})$ & $3.5 \mathrm{x} 10^{15} \mathrm{n} / \mathrm{cm}^{2} / \mathrm{s}$ \\
\hline Coolant & Liquid Sodium \\
Inlet Temperature & $330^{\circ} \mathrm{C}$ \\
Outlet Temperature & $530^{\circ} \mathrm{C}$ \\
Cooling Configuration & Loops \\
Number of Loops & 2 \\
Flow Rate per Loop & $135 \mathrm{~kg} / \mathrm{s}$ \\
\hline Fuel & $\mathrm{UO}{ }_{2}$ or UO $\mathrm{U}_{2}-\mathrm{PuO}_{2}$ \\
Enrichment & $45-90 \%{ }^{235} \mathrm{U}$ \\
Max Cladding Temperature & $70 \%$ Pu \\
Max Fuel Temperature & $710^{\circ} \mathrm{C}$ \\
\hline Operation Cycle & - \\
\hline
\end{tabular}




\begin{tabular}{|l|l|}
\hline \multicolumn{1}{|c|}{$\begin{array}{l}\text { Reactor Operating } \\
\text { Refueling }\end{array}$} & $\begin{array}{l}120 \text { days } \\
30 \text { days }\end{array}$ \\
\hline Damage Rate & $25 \mathrm{dpa} / \mathrm{yr}$ \\
\hline Irradiation Test Positions in Core & 20 \\
\hline
\end{tabular}

\subsection{Irradiation Capabilities}

There are twenty uninstrumented in-core irradiation positions that are used for fuel and material irradiation testing in BOR-60. The in-core irradiation positions are hexagonal, $4.4 \mathrm{~cm}$ wide flatto-flat, and can vary between 45 to $100 \mathrm{~cm}$ in length. There are also nine dry channels outside the reactor vessel that are $70 \mathrm{~cm}$ in length with varying diameter. The largest of the dry channels is $27 \mathrm{~cm}$ in diameter. The neutron flux values in the nine dry channels are unavailable but are expected to be relatively low. The reactor is also equipped with a horizontal beam port that has a maximum fast neutron flux of $2 \times 10^{13} \mathrm{n} / \mathrm{cm}^{2} / \mathrm{s}$.

An instrumented, independent, lead-cooled channel (ILC) was designed for testing BREST-OD300 reactor fuel.[4] The ILC is loaded or unloaded during shutdown of the reactor using a temporary storage basket. It is located in the $5^{\text {th }}$ ring in the reactor core in the irradiation cell D23 shown in Figure 5. The ILC is capable of irradiating four fuel pins with an outer diameter of $0.94 \mathrm{~cm}$ and a length of $45 \mathrm{~cm}$. It is electrically heated and the heat from the lead coolant used in the ILC is removed by the primary sodium coolant system of the reactor. The cross section of the ILC in the heat exchanger zone is shown in Figure 6. The operational parameters for the ILC are given in Table 11.

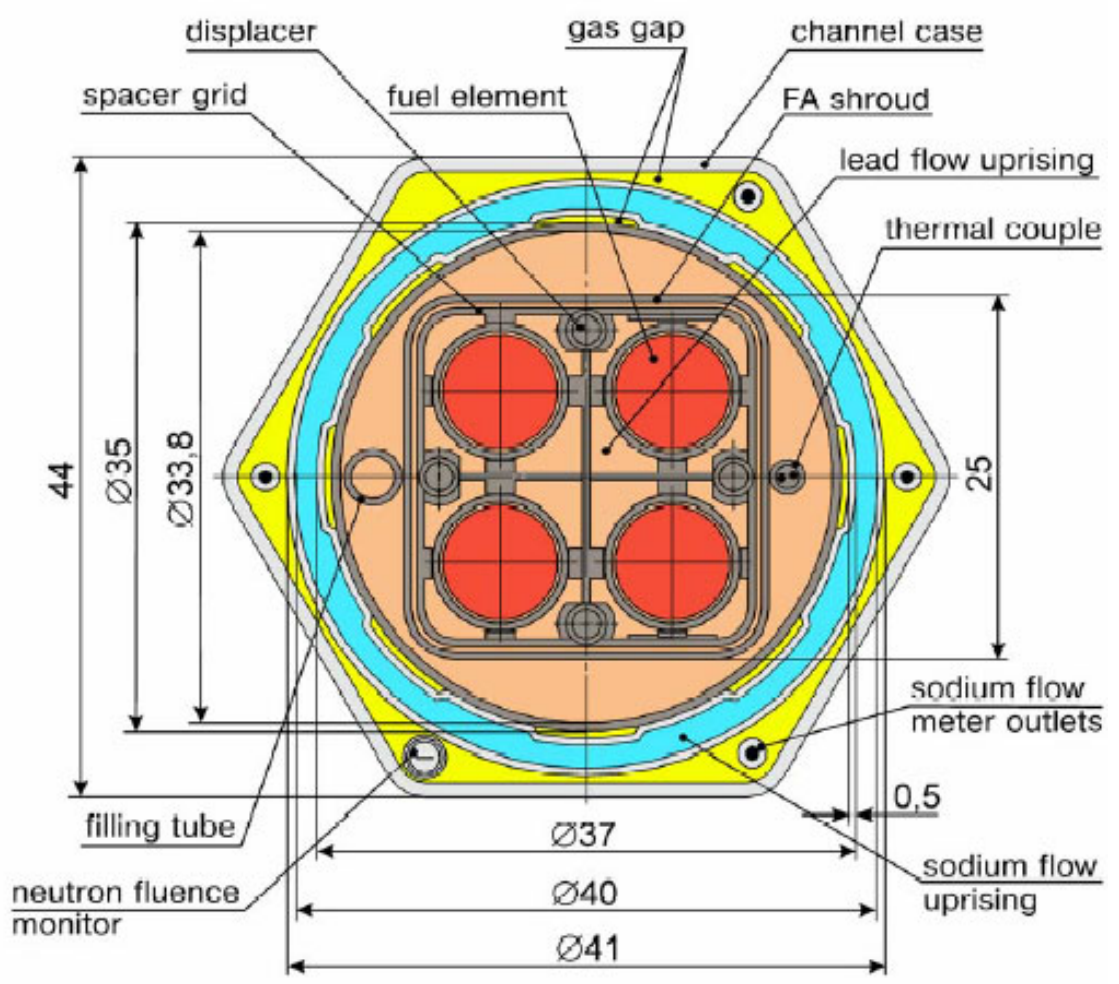

Figure 6. Cross section of the ILC in heat exchanger zone (dimensions in $\mathrm{mm}$ ) [8]. 
Table 11. Operational Parameters of the ILC [8].

\begin{tabular}{|c|c|}
\hline Parameter & Value \\
\hline Number of test fuel pins & 4 \\
\hline Length of fueled section $(\mathrm{cm})$ & 45 \\
\hline Fuel pin outer diameter $(\mathrm{cm})$ & 1.3 \\
\hline Lead coolant flow rate $\left(\mathrm{m}^{3} / \mathrm{hr}\right)$ & 1.1 \\
\hline Lead coolant velocity $(\mathrm{m} / \mathrm{s})$ & $490 / 570$ \\
\hline Lead coolant temperature, inlet/outlet of enrichment zone $\left({ }^{\circ} \mathrm{C}\right)$ & $330 / 420$ \\
\hline Sodium temperature, inlet/outlet of the capsule $\left({ }^{\circ} \mathrm{C}\right)$ & 1.9 \\
\hline Primary sodium flow rate through capsule $\left(\mathrm{m}^{3} / \mathrm{hr}\right)$ & \\
\hline
\end{tabular}

\subsection{Availability}

BOR-60 has a plant availability factor between $64 \%-75 \%$ and it appears that it will not be shutdown anytime soon. Although the reactor has several in-core irradiation positions, several irradiation campaigns are being conducted for future development of fast reactor technologies in Russia. Negotiations between the United States and Russia to obtain access to the facility could be time consuming and further delay AFCI program goals. Currently, there is only one instrumented irradiation testing rig (ILC) that is available for use. However, it is unclear if the ILC will be available for foreign users.

\subsection{Summary}

The BOR-60 reactor has performed numerous successful fuel and material irradiation campaigns. It has proven to be capable of providing a high fast neutron flux and producing damage rates that would be comparable to the proposed ATR gas test loop. However, it appears that the reactor does not have the capability of providing instrumentation for real-time monitoring of irradiation tests. The availability of the reactor for foreign institutions seems to be limited. The BOR-60 reactor might not be capable of performing the extended irradiation campaigns that are needed to support the goals specified by the AFCI program.

\subsection{HFIR}

The High Flux Isotope Reactor (HFIR), located at Oak Ridge National Laboratory (ORNL), produces one of the highest neutron fluxes of any of the world's research reactors. Two hundred researchers use the facility each year to perform neutron scattering experiments. It is also used 
for medical, industrial, and research isotope production and is the sole provider of Cf-252 in the western world.

\subsection{Reactor Characteristics}

The reactor core consists of two annular regions, as shown in Figure 7, and is approximately $61 \mathrm{~cm}$ in diameter [9]. A single flux trap is located in the center of the core and is used for material testing and isotope production. HFIR has a peak power of $85 \mathrm{MW}_{\mathrm{t}}$ and produces a peak fast flux $\left(\mathrm{E}_{\mathrm{n}}>0.1 \mathrm{MeV}\right)$ of $1.2 \times 10^{15} \mathrm{n} / \mathrm{cm}^{2} / \mathrm{s}$ and a peak thermal flux of $2.4 \mathrm{x}$ $10^{15} \mathrm{n} / \mathrm{cm}^{2} / \mathrm{s}$. The peak fast-to-thermal flux ratio is then 0.5 . Radial flux profiles across the midcore horizontal plane are shown in Figure 7. The specifications and operating conditions for HFIR is shown in Table 12.

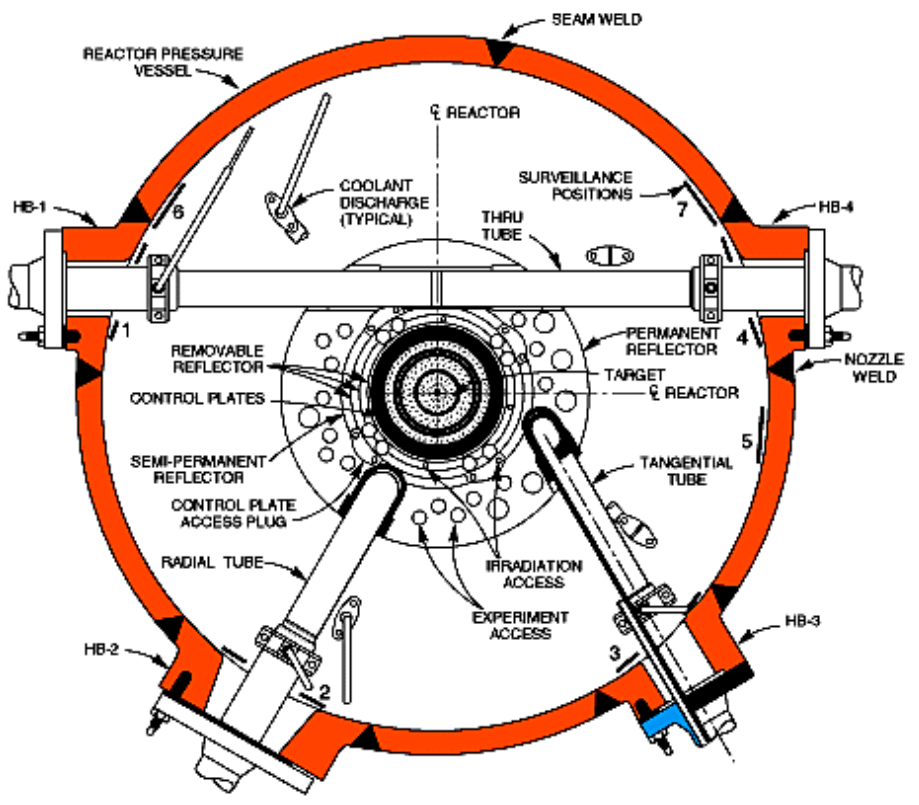

Figure 7. Sectional plan view of the HFIR core [9]. 


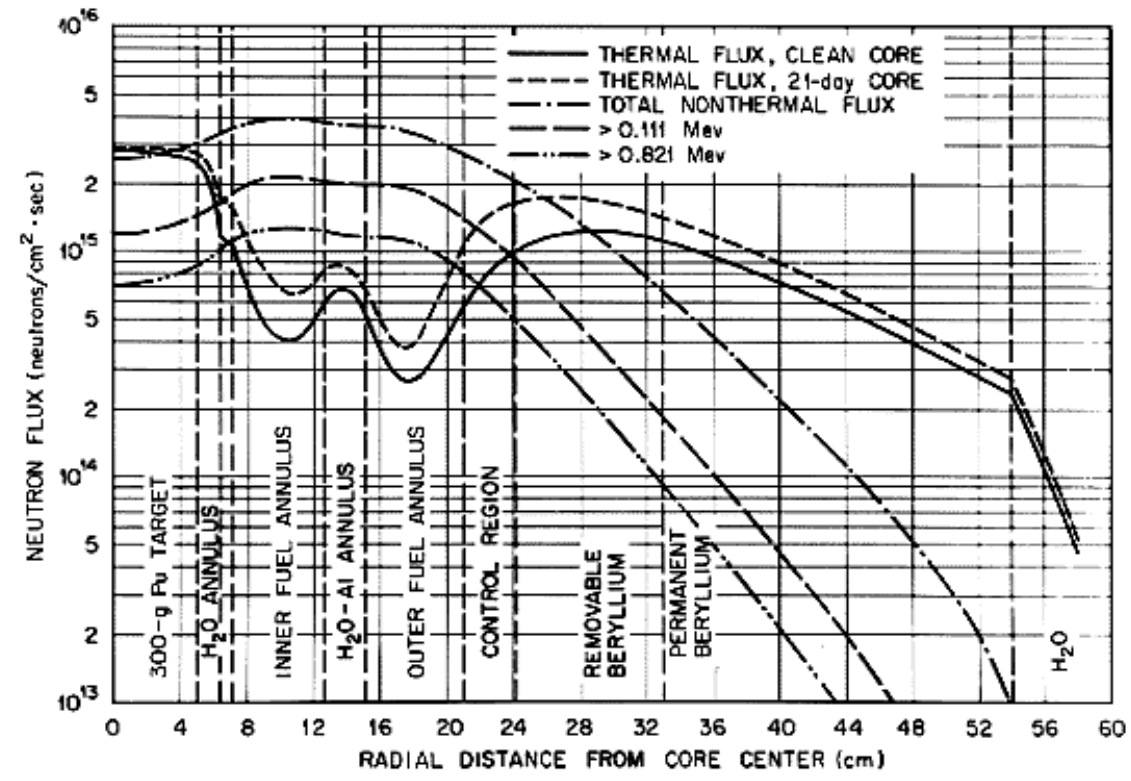

Figure 8. Typical radial neutron flux distributions at core horizontal midplane with reactor operating at $100 \mathrm{MW}_{\mathrm{t}}[9]$.

Table 12. Specifications and Operating Conditions for HFIR [10].

\begin{tabular}{|l|l|}
\hline Type & Thermal Reactor, Tank \\
\hline Location & Oak Ridge, Tennessee, USA \\
\hline Operator & Oak Ridge National Laboratory \\
\hline Annual Operating Cost & $\$ 33 \mathrm{M}$ (U.S.) \\
\hline Date of First Criticality & $8 / 1 / 1965$ \\
\hline Thermal Power & $85 \mathrm{MW}$ \\
\hline Electrical Power Output & $\mathrm{N} / \mathrm{A}$ \\
\hline Core & \\
Diameter & $0.61 \mathrm{~m}$ \\
Height & $0.50 \mathrm{~m}$ \\
Number of Elements & 171 \\
Plates per Element & 14 \\
Fast Flux (E $>0.1 \mathrm{MeV})$ & $1.2 \times 10^{15} \mathrm{n} / \mathrm{cm}^{2} / \mathrm{s}$ (target bundle) \\
Thermal Flux (E $\left.{ }_{\mathrm{n}}<0.1 \mathrm{MeV}\right)$ & $2.4 \times 10^{15} \mathrm{n} / \mathrm{cm}^{2} / \mathrm{s}$ (target bundle) \\
Fast to Thermal Flux Ratio & $0.5($ target bundle) \\
\hline Coolant & Light Water $^{\circ}$ \\
Inlet Temperature & $49^{\circ} \mathrm{C}$ \\
Outlet Temperature & $69^{\circ} \mathrm{C}$ \\
Cooling Configuration & Loops \\
Number of Loops & 8 \\
\hline Fuel & $\mathrm{UO}_{2}$ \\
Enrichment & $93 \% \mathrm{U}^{235}$ \\
\hline
\end{tabular}




\begin{tabular}{|l|l|}
\hline $\begin{array}{l}\text { Operation Cycle } \\
\text { Reactor Running }\end{array}$ & $21-23$ days \\
Refueling & 6 days \\
Days of Operation per Year & 285 days \\
\hline $\begin{array}{l}\text { Test Volume (flux trap) } \\
\text { Diameter } \\
\text { Length }\end{array}$ & $12.7 \mathrm{~cm}$ \\
\hline Damage Rate & $50 \mathrm{~cm}$ \\
\hline Loops Use & N/A \\
\hline
\end{tabular}

\subsection{Irradiation Capabilities}

Many experiments can be performed in the flux trap by using the hydraulic tube capsule located in one of the 31 target positions in the flux trap. Six peripheral target positions are also available in the flux trap. A typical hydraulic tube capsule is shown in Figure 9 and the 31 target positions are shown in Figure 10. Nine vertically stacked capsules can be placed in the flux trap one time and can hold samples with a diameter of $0.65 \mathrm{~cm}$ with a length of $5.56 \mathrm{~cm}$. The maximum fast neutron flux in the flux trap is located in the peripheral target positions, although a steep radial gradient in the thermal neutron flux exists at these locations. The dimensions of the samples to be placed in the peripheral target positions are similar to the dimensions for the hydraulic tube capsule. All experiments located in the peripheral target positions are uninstrumented

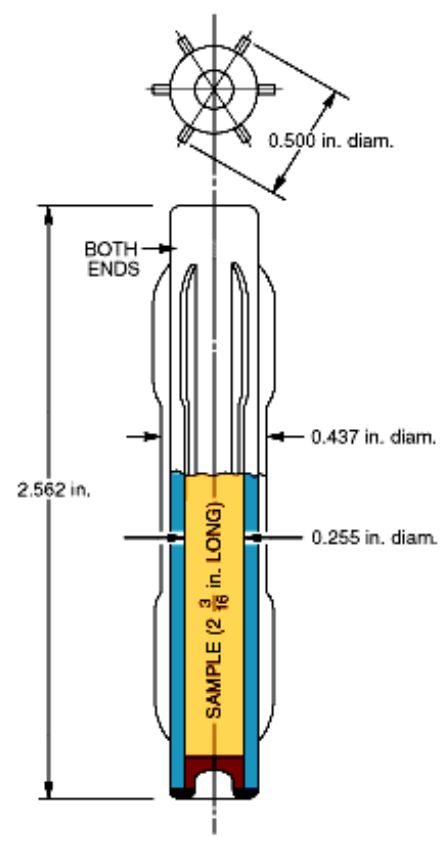

Figure 9. Hydraulic tube capsule assembly [9]. 


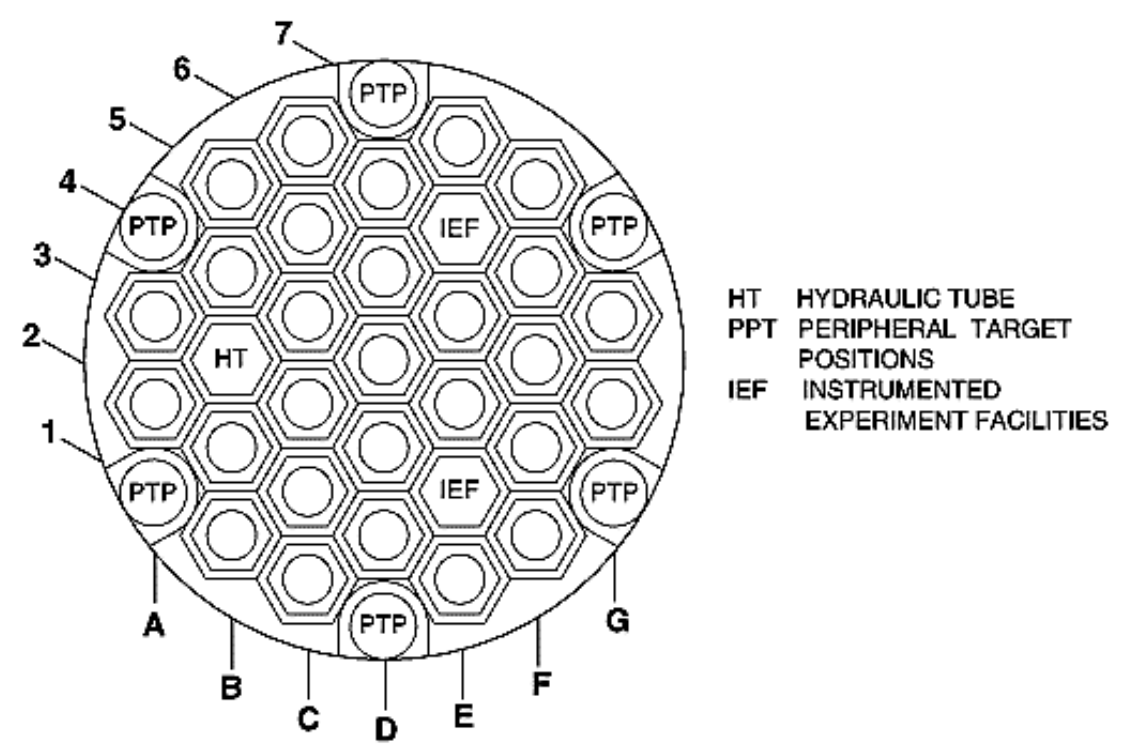

Figure 10 Target loading in flux trap (1 to 7 and $\mathrm{A}$ to $\mathrm{G}$ indicate rows) [9].

Along with the flux trap, there are eight removable beryllium (RB) irradiation positions that have been used for high temperature gas cooled reactor fuel irradiations and the production of isotopes. The RB positions have an inner diameter of $4.6 \mathrm{~cm}$ and a length of $54.6 \mathrm{~cm}$. Instrumented or uninstrumented experiments can be placed in these positions. The fast neutron flux through the beryllium reflector varies from $2 \times 10^{14}-1 \times 10^{15} \mathrm{n} / \mathrm{cm}^{2} / \mathrm{s}$ while the average thermal flux is approximately $1.8 \times 10^{15} \mathrm{n} / \mathrm{cm}^{2} / \mathrm{s}$. This results in a fast-to-thermal flux ratio varying between 0.11 and 0.56 at $100 \mathrm{MW}_{\mathrm{t}}$.

\subsection{Availability}

The HFIR facility is operated $78 \%$ of the time during the year and it is unclear at this point what the availability will be for experimenters to have access to the flux trap. Due to the high demand of the reactor (up to 200 researchers per year), it is believed that it would be difficult to perform the extended irradiation tests that are needed to support the AFCI and GEN IV goals.

\subsection{Summary}

The HFIR is one of the United States most powerful research reactors. It offers a wide variety of neutron fluxes throughout the core but is limited by the small fast-to-thermal flux ratio, which is important when simulating a fast reactor environment. It appears that significant modifications would have to be performed on the core similar to the ones being proposed for the ATR gas test loop to meet the demand of the United States nuclear program.

\subsection{MATERIALS TEST STATION}

The proposed Materials Test Station (MTS) located at Los Alamos National Laboratory (LANL) will utilize the existing Los Alamos Neutron Science Center (LANSCE) linear accelerator. The final design of this system has not been completed but three target and coolant options are being considered. These are: (1) light water coolant with tungsten plates $\left(\mathrm{W} / \mathrm{H}_{2} \mathrm{O}\right),(2)$ lead bismuth 
eutectic (LBE) as both target and coolant, and (3) LBE-coolant with a clad-uranium molybdenum plate target (U/LBE). Present planning is for water-cooled tungsten plates and to become operational in mid 201011.

\subsection{Characteristics}

The MTS will have a split target geometry to create a flux trap between the two targets. A stalk assembly will be used to center the materials and target with the $800 \mathrm{MeV}$ proton beam, which will be rastered over the target area. The stalk assembly is equipped with cooling, instrumentation, control power, heating power, beam diagnostics, and a means for sample removal. A concept for the lower end of the stalk assembly is shown in Figure 11, The stalk assembly will be located inside of a vacuum tank.

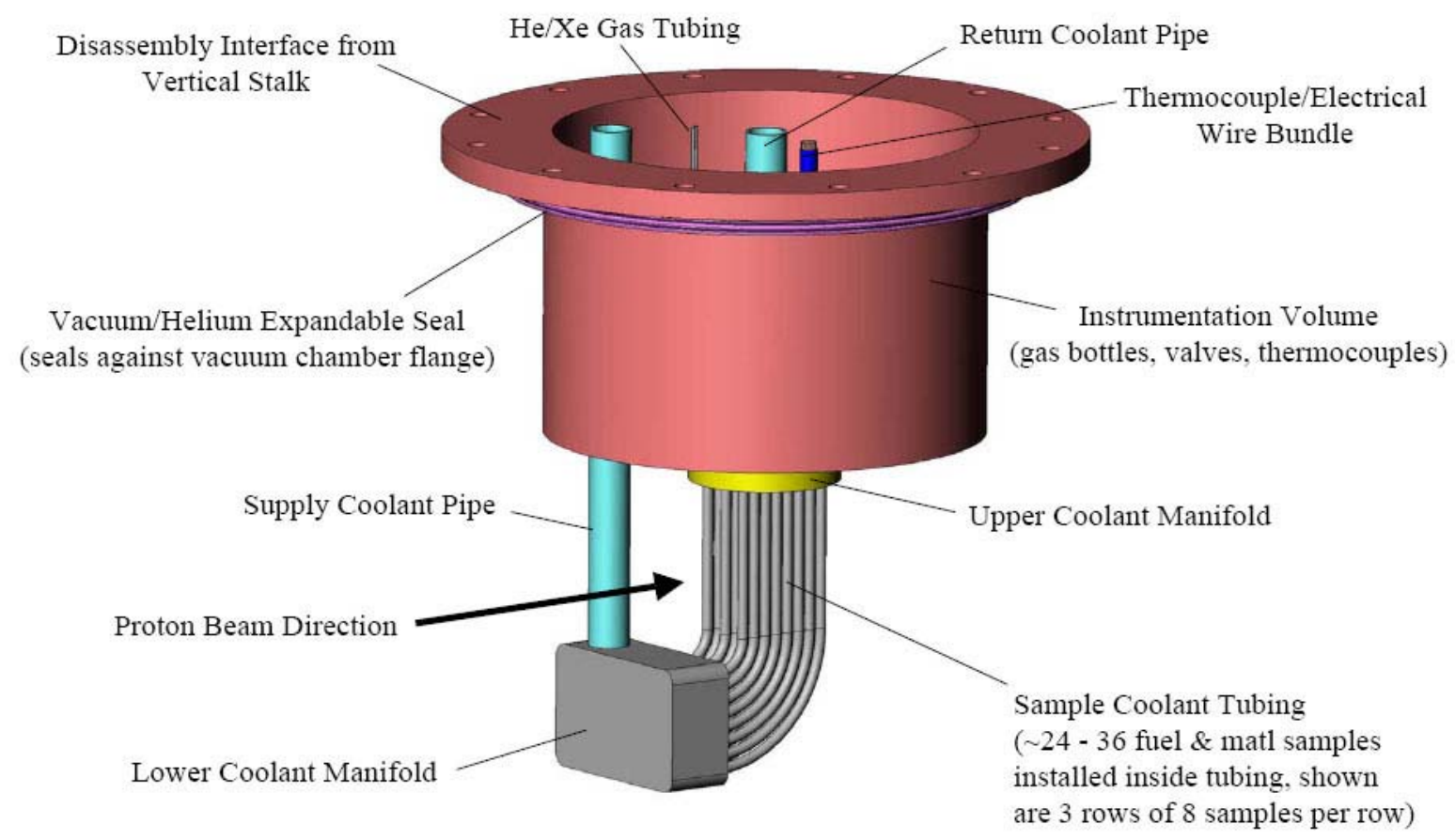

Figure 11.MTS stalk assembly concept [11].

Optimization studies have been performed on several target/coolant options. It is predicted that the lead-bismuth eutectic (LBE) configuration will produce maximum fast neutron flux of $1.4 \mathrm{x}$ $10^{15} \mathrm{n} / \mathrm{cm}^{2}$ in the center of the tungsten targets, but there are substantial spatial gradients in the neutron flux intensity, as shown in Figures 12 and 13. These results are assumed to be similar to those for water-cooled tungsten $\left(\mathrm{W} / \mathrm{H}_{2} \mathrm{O}\right)$ targets [12]. The peak neutron flux in the test specimen positions is midway between the two targets and extends over a few of the test positions, as shown in Figures 12 and 13. Table 13 compares $\mathrm{W} / \mathrm{H}_{2} \mathrm{O}$ and $\mathrm{U} / \mathrm{LBE}$ target/coolant options for the highest-powered fuel rod in the center fuel module located between the two sets of targets. 


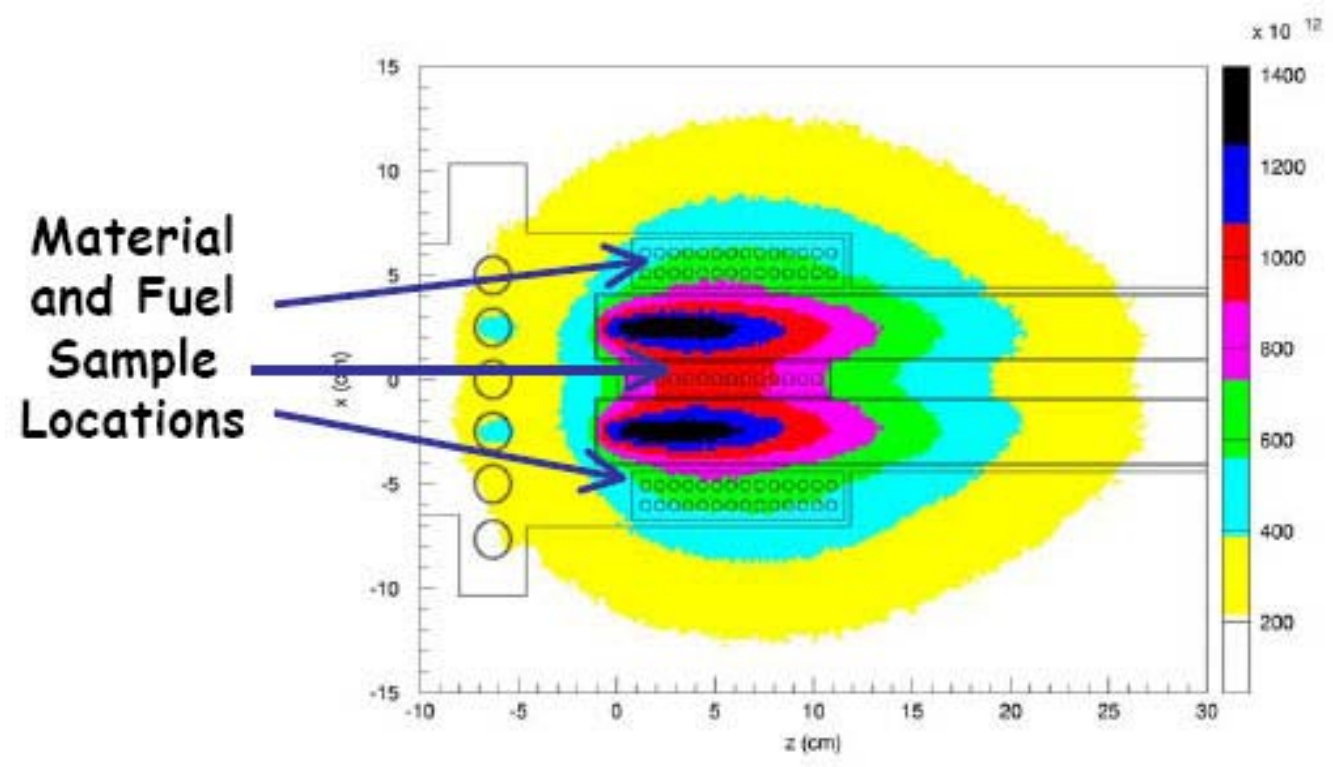

Figure 12. Fast neutron flux map $\left(\mathrm{E}_{\mathrm{n}}>0.1 \mathrm{MeV}\right)$ for the LBE-cooled $\mathrm{U}_{10} \mathrm{Mo}$ target configuration in MTS $[11,12]$.

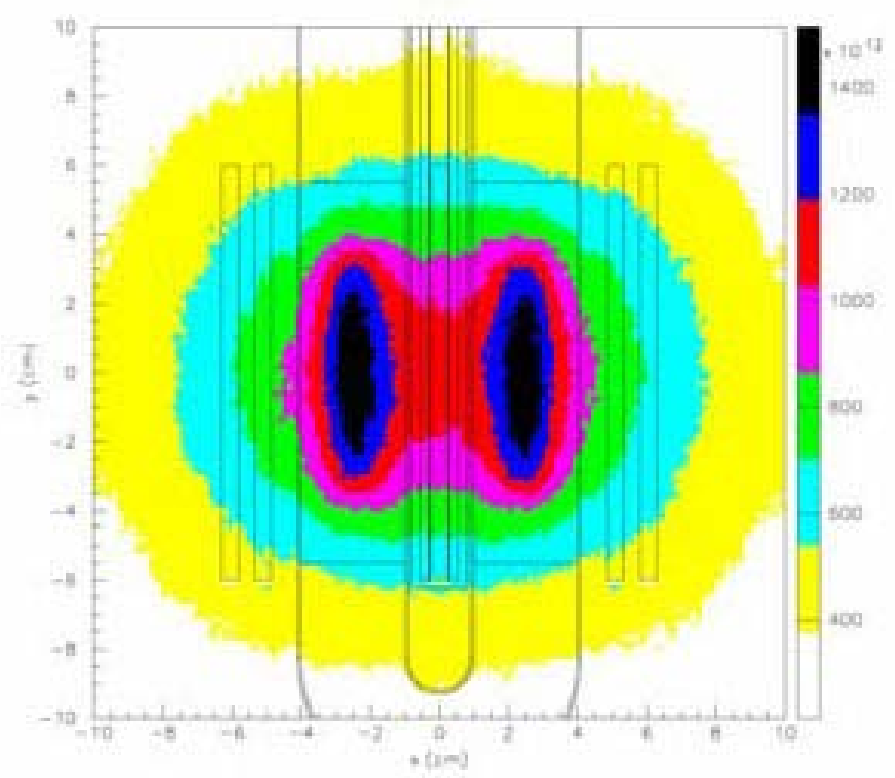

Figure 13. Fast neutron flux map $\left(\mathrm{E}_{\mathrm{n}}>0.1 \mathrm{MeV}\right)$ for a LBE-cooled $\mathrm{U}_{10}$ Mo target $(\mathrm{z}=3.5$ to 5.5) [12]. 
Table 13. Comparison of the $\mathrm{W} / \mathrm{H}_{2} \mathrm{O}$ and $\mathrm{U} / \mathrm{LBE}$ Options [12].

\begin{tabular}{|c|c|c|}
\hline Coolant & LBE & Light Water \\
\hline Coolant Inlet Temperature $\left({ }^{\circ} \mathrm{C}\right)$ & 300 & 23 \\
\hline Coolant Velocity $(\mathrm{m} / \mathrm{s})$ & 2.00 & 4.75 \\
\hline Mass Flow Rate in Central Region $(\mathrm{kg} / \mathrm{s})$ & 10.40 & 2.39 \\
\hline Coolant Exit Temperature $\left({ }^{\circ} \mathrm{C}\right)$ & 322.2 & 29.4 \\
\hline Peak Clad Surface Temperature $\left({ }^{\circ} \mathrm{C}\right)$ & 364.7 & 128.8 \\
\hline Peak Clad Temperature $\left({ }^{\circ} \mathrm{C}\right)$ & 387.2 & 179.2 \\
\hline Peak Fuel Temperature $\left({ }^{\circ} \mathrm{C}\right)$ & 452.3 & 324.2 \\
\hline
\end{tabular}

LANL has proven experience in operating an accelerator driven system with a water-cooled, tungsten target $\left(\mathrm{W} / \mathrm{H}_{2} \mathrm{O}\right)$ and it appears that the MTS will use this target/coolant pair with a plate geometry in their final design [13]. The MTS will run a continuous 6 month irradiation campaign per year and it is estimated that it will take 12 months of irradiating an iron sample in the center module to achieve a damage of $15-17 \mathrm{dpa}$ for a $\mathrm{W} / \mathrm{H}_{2} \mathrm{O}$ configuration. Based on the time of the irradiation campaigns, the damage rate is $7.5-8.5 \mathrm{dpa} /$ year.

\subsection{Irradiation Capabilities}

\subsubsection{Irradiation Positions}

The MTS will have a number of sample irradiation positions. Latest indications are that there will be $24-36$ such positions, each with a maximum capsule diameter of $15 \mathrm{~mm}$, with an active irradiation length of $12 \mathrm{~cm}$ [13]. This is illustrated in Figure 14.

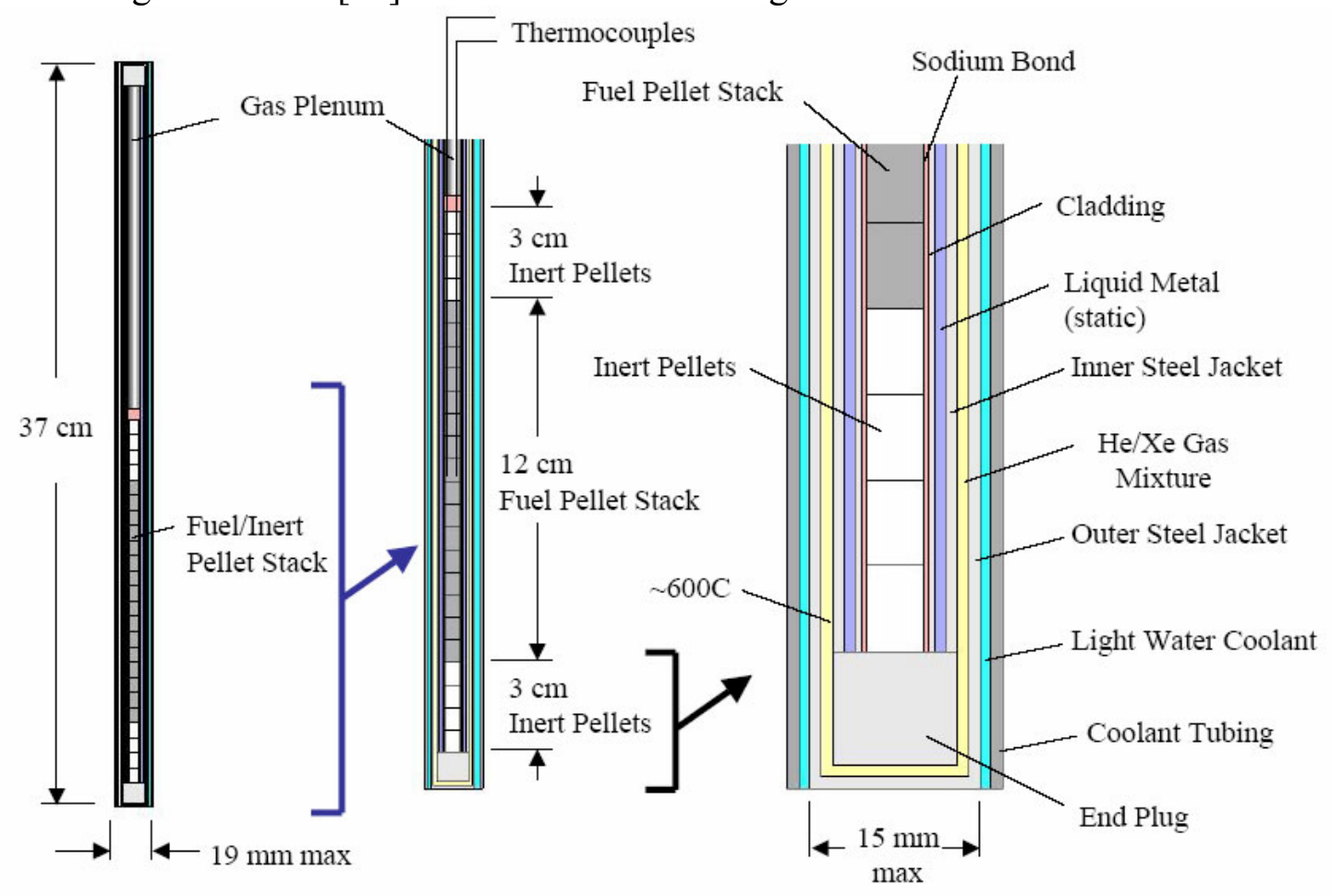

Figure 14.MTS irradiation facility configuration [13]. 
As shown in Figure 12, a few positions between the two spallation targets will experience the highest neutron flux $\left(\sim 1.0 \times 10^{15} \mathrm{n} / \mathrm{cm}^{2} / \mathrm{s}\right)$, whereas the majority $(90 \%)$ of the sample positions will see a fast neutron flux that varies between $3.0 \times 10^{14} \mathrm{n} / \mathrm{cm}^{2} / \mathrm{s}-7.0 \times 10^{14} \mathrm{n} / \mathrm{cm}^{2} / \mathrm{s}$.

\subsubsection{Energy Spectrum}

The MTS has a high-energy neutron tail, a characteristic of all spallation targets. The lethargy ${ }^{\mathrm{a}}$ neutron flux spectrum, which describes neutron collisions, as a function of neutron energy of the MTS and a typical advanced liquid metal reactor (ALMR) are similar between the energies of $1 \mathrm{keV}$ and $10 \mathrm{MeV}$. At neutron energies greater than $10 \mathrm{MeV}$, the lethargy flux of a typical fast reactor decreases quickly while the lethargy flux of the MTS remains between $10^{13}$ and $10^{12} \mathrm{n} / \mathrm{cm}^{2} / \mathrm{s}$ up to $1000 \mathrm{MeV}$. This is illustrated in Figure 15 . The high-energy tail of the MTS adversely impacts fuel and material irradiations.

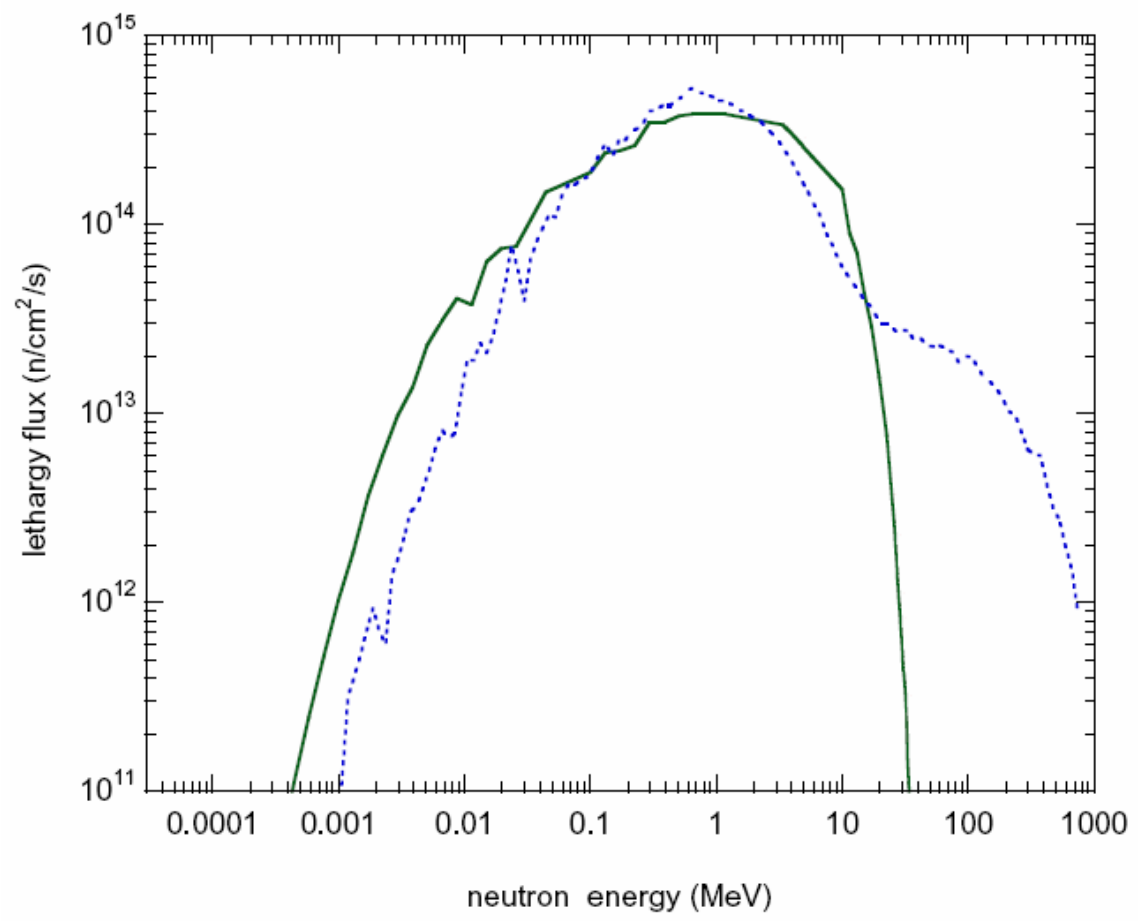

Figure 15.MTS lethargy flux spectrum compared to a typical fast reactor spectrum [11].

A proposal has been made to increase the proton beam current from $0.7-1.0 \mathrm{~mA}$ to $1.6-2.0$ $\mathrm{mA}$, and to increase beam energy from $800 \mathrm{MeV}$ to $3 \mathrm{Gev}$. The current increase would increase the neutron flux intensity in most of the irradiation positions to near or greater than $1.0 \times 10^{15}$ $\mathrm{n} / \mathrm{cm}^{2} / \mathrm{s}$. The energy increase would add more spallation neutrons, and it would significantly enhance the super-energetic tail of the energy spectrum, as shown in Figure 16.

That figure shows the data of Figure 15, but in addition results of MCNP [14] calculations averaged over the central test volume between the two target modules for water-cooled tungsten targets for $1 \mathrm{~mA}$ proton beam current at $800 \mathrm{MeV}$ and $3 \mathrm{GeV}$. Also shown is the spectrum available in the Advanced Test Reactor with booster fuel and a thermal neutron absorber.

\footnotetext{
${ }^{a}$ Lethargy refers to the logarithm of the ratio of initial to final energies over an energy interval.
} 


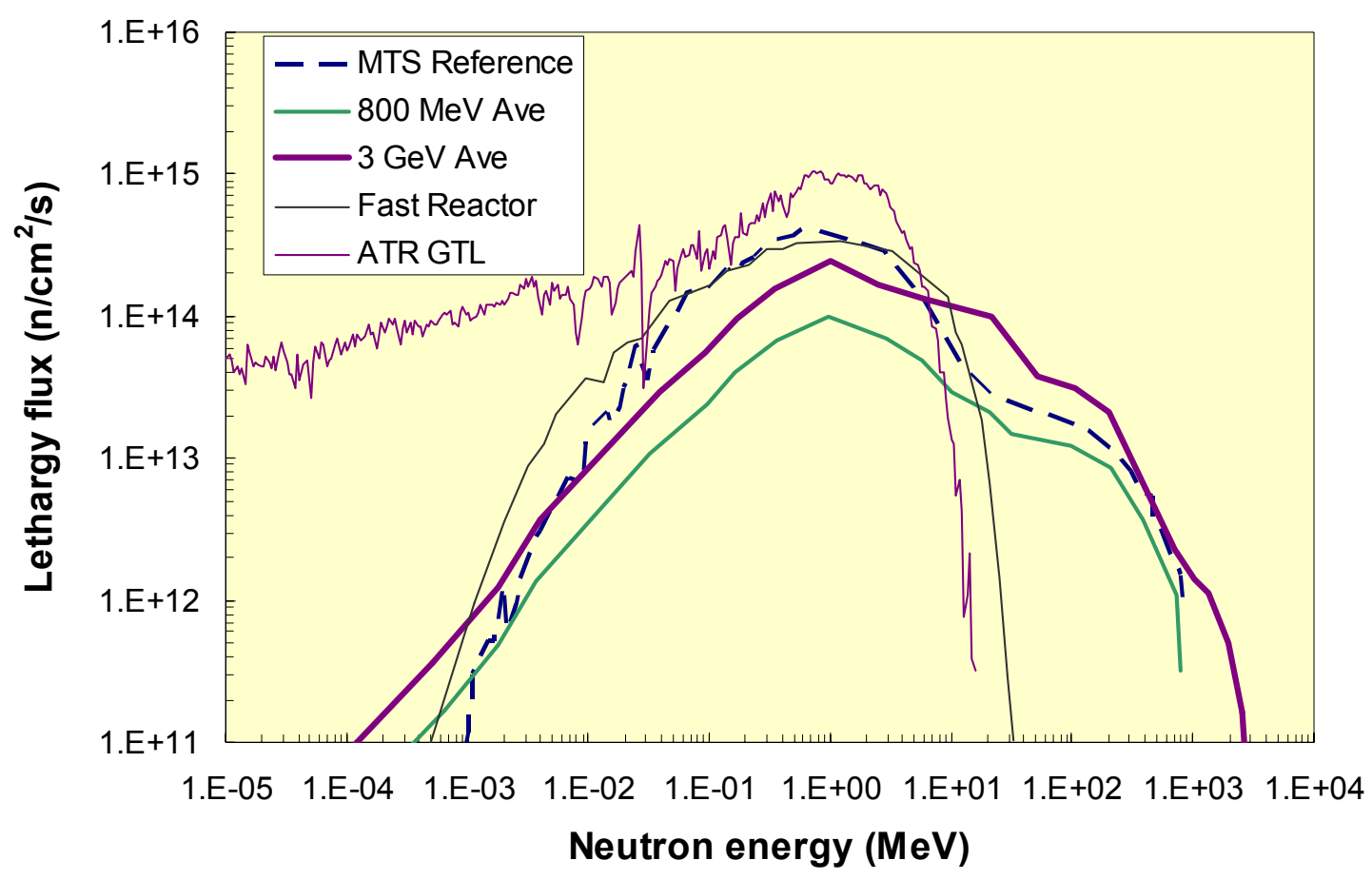

Figure 16.Comparison of neutron energy spectra.

Figure 17 shows the differences in spatial distribution of the neutron flux intensity between $800-\mathrm{MeV}$ proton generated neutrons and those from a $3-\mathrm{GeV}$ proton beam. The spatial distributions in Figure 17(a) are similar to those of Figure 12. Those of Figure 17(b) are slightly elongated axially compared with those of Figure 17 (a) and the flux intensity is greater. Both distributions show substantial flux intensity gradients in the test positions outside the beam targets but relatively uniform flux intensity in the middle of the space between the beam targets.

\subsection{Availability}

The MTS is designed to be used specifically for irradiation testing of fuels and materials to support the United States nuclear programs. It is estimated that the availability to experimenters during the operating months will be close to $95 \%$.

\subsection{Summary}

Costs to perform the required research and modify the existing LANSCE linear accelerator and construct the MTS have not been published. The MTS is attractive because it has the capability to use $\mathrm{PbBi}, \mathrm{Na}, \mathrm{He}$, and water as coolants to simulate the environment of a fast reactor, though present plans are apparently to rely on water. It is expected to have a high availability for experimenters. However, at this time, it is in the design stage, and the decision to commit capital funding to build the MTS has not been made. 

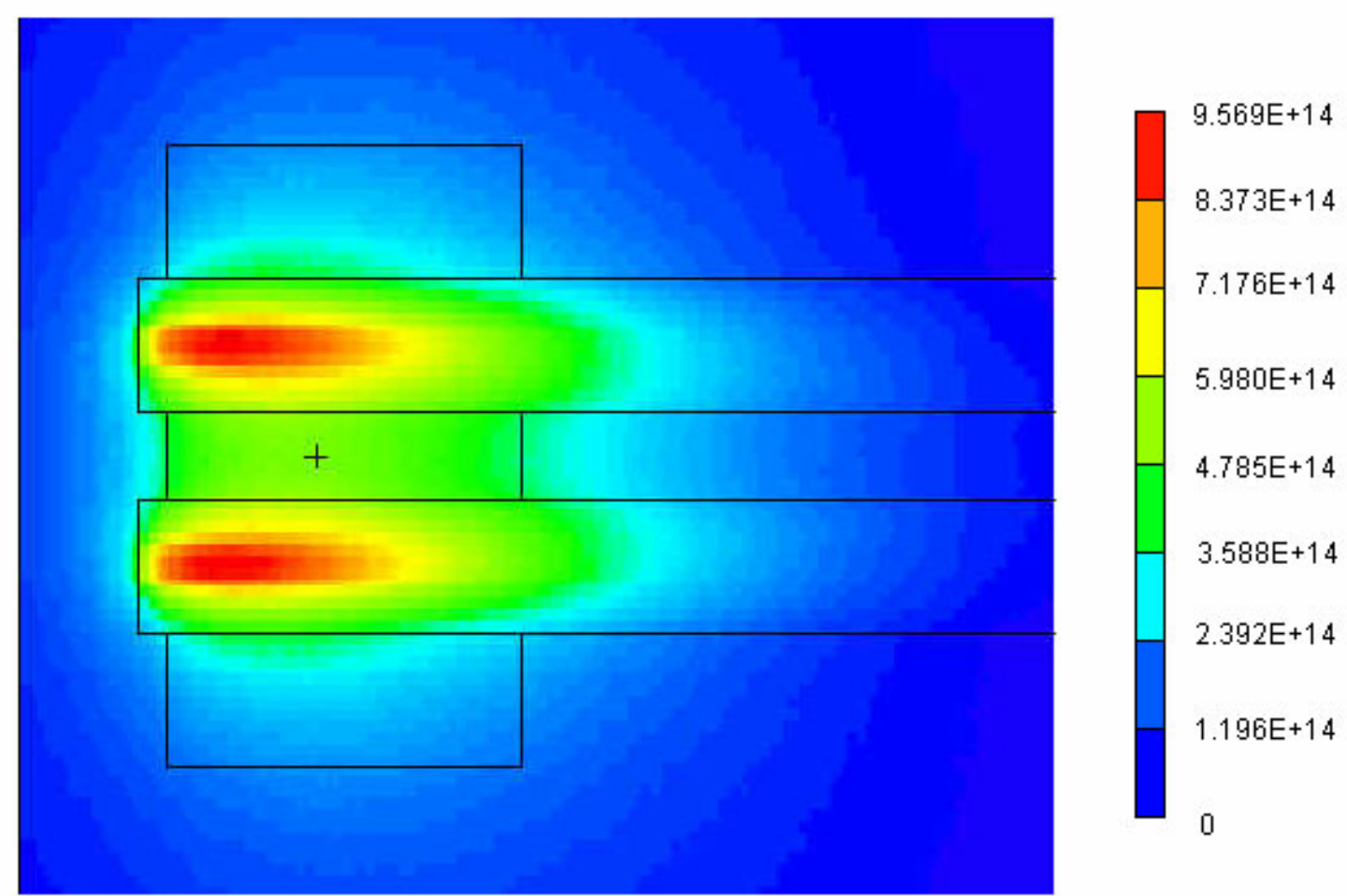

(a)

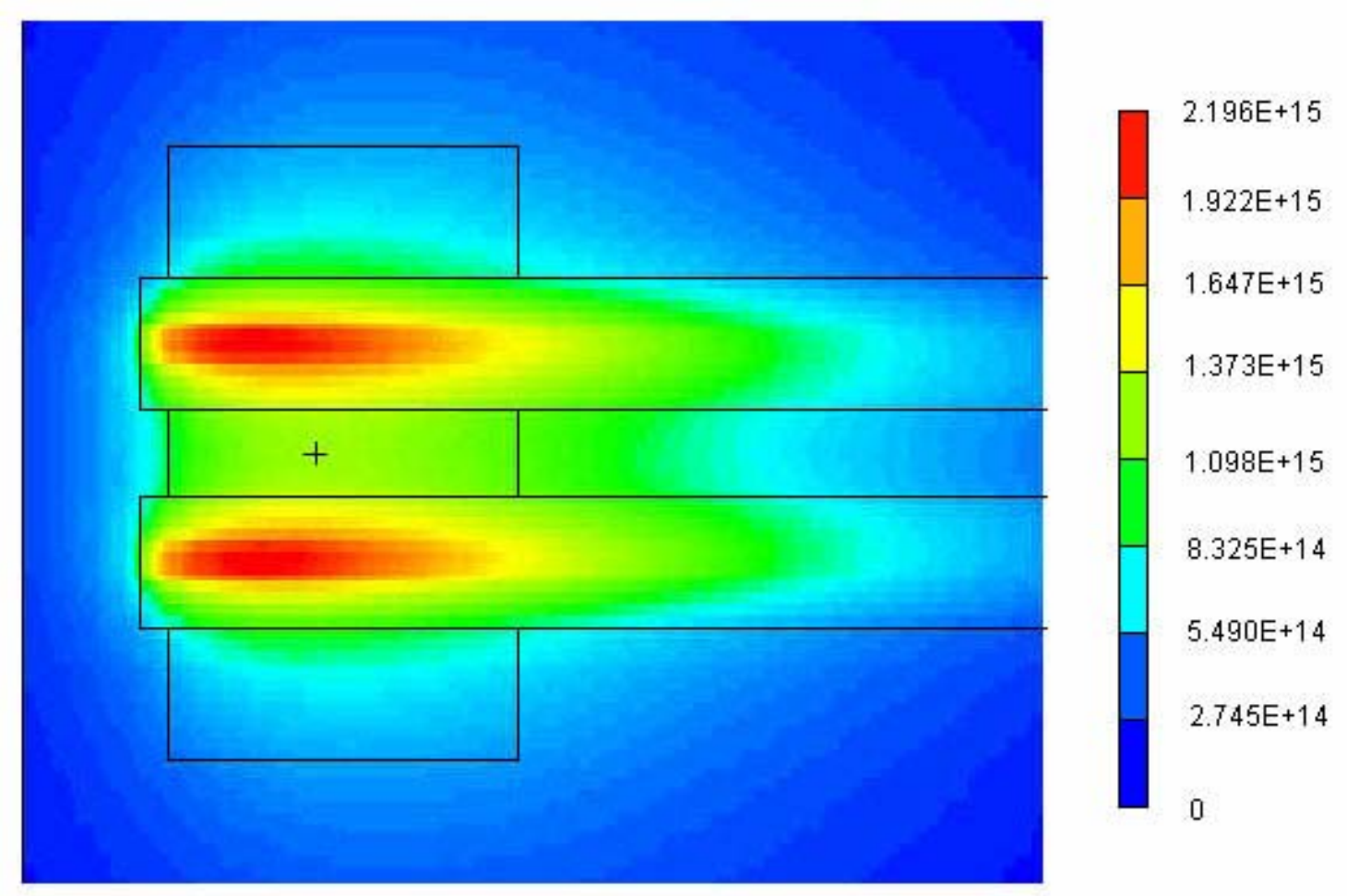

(b)

Figure 17.MCNP calculation results for water-cooled tungsten targets in MTS for a 1-mA proton beam at (a) $800 \mathrm{MeV}$, and (b) $3 \mathrm{GeV}$ beam energy. 


\subsection{ADVANCED TEST REACTOR}

\subsection{Characteristics}

The ATR was originally commissioned in 1967 with the primary mission of materials and fuels testing for the United States Naval Reactors Program. It is the highest power research reactor operating in the United States. Its large test volumes make it attractive for irradiations of materials and components. Though it has been operating for many years, the ATR is expected to remain operational until at least the year 2050. The ATR is designed to evaluate the effects of intense radiation on material samples, especially nuclear fuels. The principal customer for the reactor over most of its lifetime has been the U.S. DOE Naval Reactors Program. Other uses include isotope production for medical, industrial, environmental, agricultural and research applications. Irradiation services are provided for government programs as well as private firms and consortiums.

The ATR was designed to provide large-volume, high-flux test locations. A unique serpentine fuel arrangement (Figure 18) provides nine high-intensity neutron flux traps and 68 additional irradiation positions inside the reactor core reflector tank, each of which can contain multiple experiments. Thirty-four more low-flux irradiation positions are in the two capsule irradiation tanks outside the core. The four flux traps positioned within the corner lobes of the reactor core are almost entirely surrounded by fuel, as is the center position. Four other flux trap positions between the lobes of the core have fuel on three sides. The curved fuel arrangement brings the fuel closer on all sides of the flux trap positions than is possible in a rectangular grid. Effects from years of radiation in a normal power reactor can be duplicated in months or even weeks in the ATR.

Testing can be performed in three major kinds of experiment facilities in the ATR: (1) pressurized water test loops installed in some flux traps that replicate a variety of reactor conditions; (2) instrumented lead experiments that provide real-time measurements and temperature and atmosphere control in the experiment capsules; or (3) simple drop-in capsule experiments in reflector or core irradiation positions. 


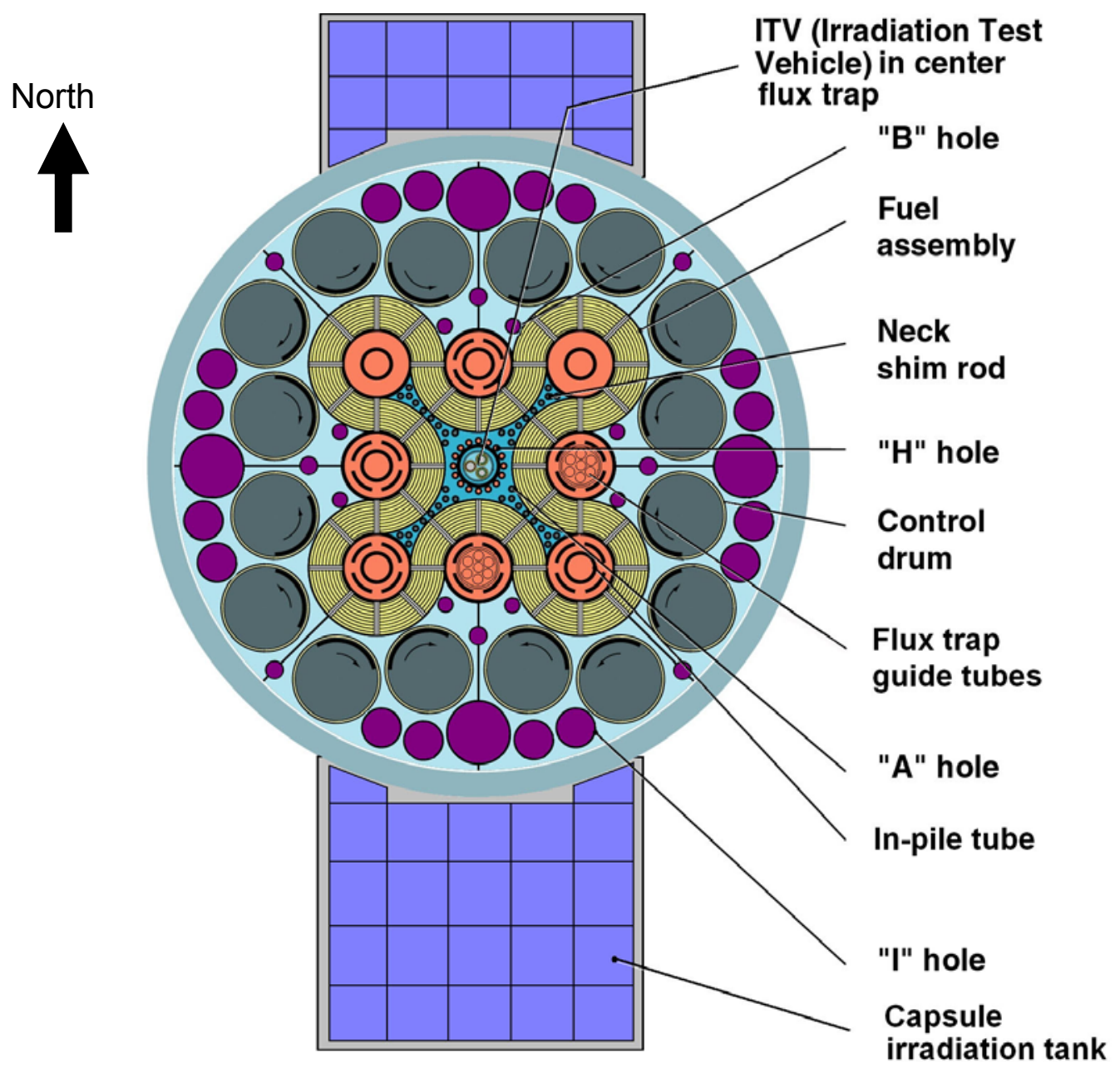

Figure 18. Basic configuration of the ATR core showing irradiation positions.

General characteristics for the ATR are listed in Table 14. Table 15 lists neutron fluxes and other parameters for the various test positions. Fluxes are values at the current standard operating power of $110 \mathrm{MW}$. They can be increased locally in the corner (NW, NE, SE, SW) flux traps by operating the corner lobe at a higher power level.

\subsection{Irradiation Capabilities}

The ATR's unique control device design permits large power shifts among the nine flux traps. The ATR uses a combination of control cylinders or drums and neck shim rods. The control cylinders rotate hafnium plates toward and away from the core, and the shim rods, which withdraw vertically, are individually inserted or withdrawn to adjust power. Within bounds, the power level in each corner lobe of the reactor can be controlled independently. 
Table 14. ATR general characteristics.

Reactor
Thermal Power
Power Density
Maximum Thermal Neutron Flux
Maximum Fast Flux
Number of Flux Traps
Number of Experiment Positions
Core
Number of fuel assemblies
Active length of Assemblies
Number of fuel plates per assembly
Uranium-235 content of an assembly
Total core load
Coolant
Design Pressure
Design Temperature
Reactor coolant
Maximum Coolant Flow Rate
Coolant Temperature (Operating)

$250 \mathrm{MW}_{\text {th }}{ }^{\mathrm{a}}$

$1.0 \mathrm{MW} / \mathrm{L}$

$1.0 \times 10^{15} \mathrm{n} / \mathrm{cm}^{2}-\mathrm{sec}^{\mathrm{b}}$

$5.0 \times 10^{14} \mathrm{n} / \mathrm{cm}^{2}-\mathrm{sec}^{\mathrm{b}}$

9

$68^{\mathrm{c}}$

40

$1.2 \mathrm{~m}(4 \mathrm{ft})$

19

$1,075 \mathrm{~g}$

$43 \mathrm{~kg}^{\mathrm{d}}$

2.7 MPa (390 psig)

$115^{\circ} \mathrm{C}\left(240^{\circ} \mathrm{F}\right)$

Light water

$3.09 \mathrm{~m}^{3} / \mathrm{s}(49,000 \mathrm{gpm})$

$<52^{\circ} \mathrm{C}\left(125^{\circ} \mathrm{F}\right)$ inlet, $71^{\circ} \mathrm{C}$

$\left(160^{\circ} \mathrm{F}\right)$ outlet

a. Maximum design power. ATR is seldom operated above $110 \mathrm{MW}_{\text {th }}$

b. These parameters are based on the full $250 \mathrm{MWth}$ power level and will be proportionally reduced for lower reactor power levels.

c. Only 66 of these are available for irradiations.

d. Total U-235 always less because of burn-up.

Powered with highly enriched uranium, the ATR has a maximum thermal power rating of $250 \mathrm{MW}_{\text {th }}$ with a maximum unperturbed thermal neutron flux rating of $1.0 \times 10^{15} \mathrm{n} / \mathrm{cm}^{2}-\mathrm{s}$. While the ATR is capable of operation at that power, in recent years it has only occasionally operated at thermal powers greater than $110 \mathrm{MW}_{\text {th }}$.

The axial flux profile over the 1.2-m (4-ft) core height is approximately a cosine distribution, as shown in Figure 19. The vertical distance from the core mid-plane at which the flux falls from its peak value to $80 \%$ of that is about $45 \mathrm{~cm}$ (17.7 inches). 


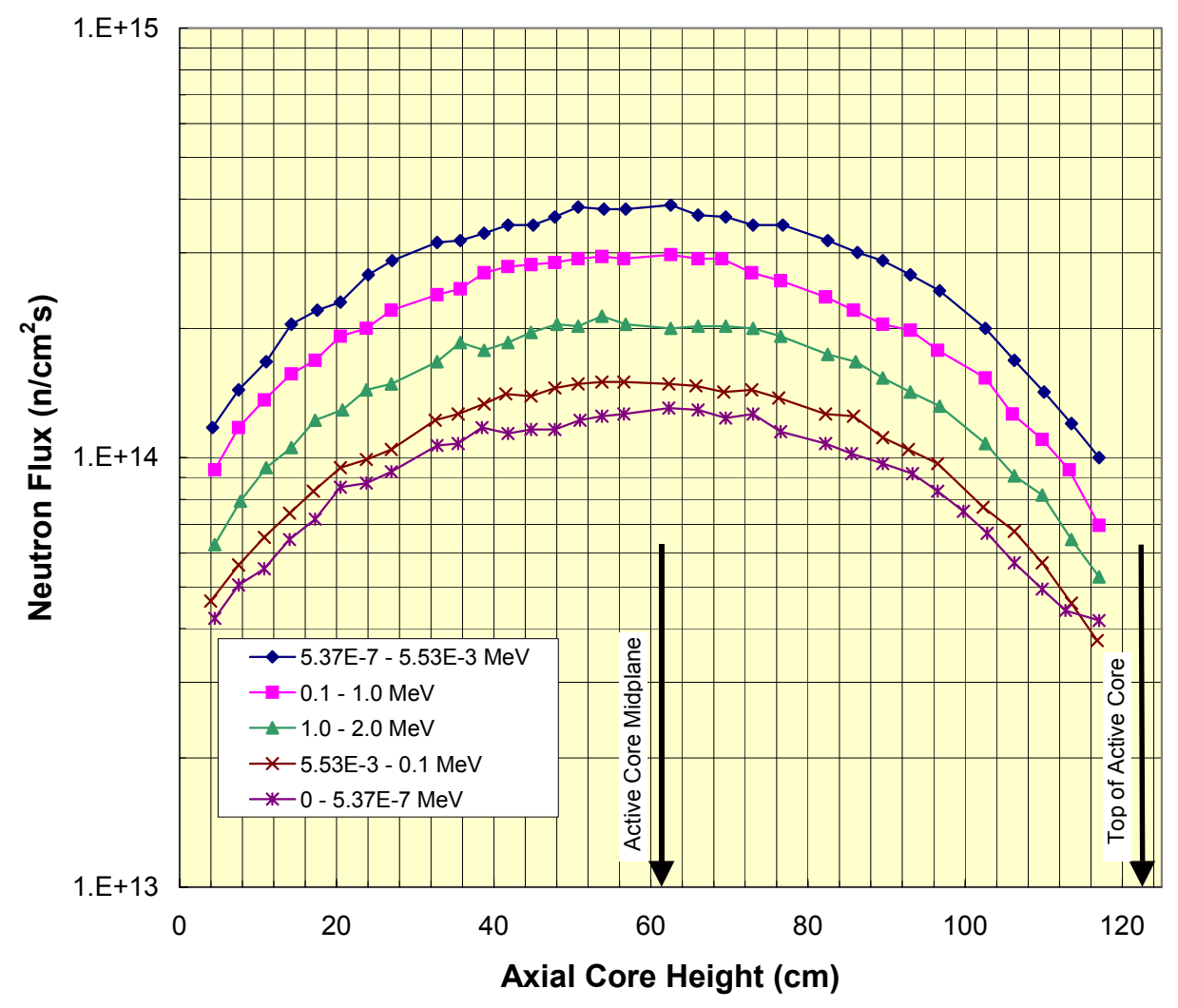

Figure 19.Unperturbed five-energy-group neutron flux intensity profiles over the active core length of the ITV in the ATR center flux trap for total reactor power of $125 \mathrm{MWth}$.

\subsection{Availability}

The reactor operational availability is approximately $75 \%$ except during core internals changeouts, which require several months at nominally 8 - to 10 -year intervals. These periods are used to replace the beryllium reflector, outer shim control cylinders and certain other core components.

Many of the major irradiation locations are occupied by the DOE Naval Reactors Program. The ones usually available are the Central, E, and S flux traps.

Though it has been operating since 1967, the ATR is expected to remain operational until at least the year 2050 . 
Table 15. Approximate peak flux values for various ATR capsule positions for a reactor power of $110 \mathrm{MW}_{\text {th }}\left(22 \mathrm{MW}_{\text {th }}\right.$ in each lobe $)$.

\begin{tabular}{|c|c|c|c|c|}
\hline Position & $\begin{array}{l}\text { Diameter } \\
(\mathrm{cm} / \mathrm{in})^{\mathrm{a}}\end{array}$ & $\begin{array}{l}\text { Thermal Flux } \\
\left(\mathrm{n} / \mathrm{cm}^{2}-\mathrm{s}\right)^{\mathrm{b}}\end{array}$ & $\begin{array}{l}\text { Fast Flux } \\
(\mathrm{E}>1 \mathrm{MeV}) \\
\left(\mathrm{n} / \mathrm{cm}^{2}-\mathrm{s}\right)\end{array}$ & $\begin{array}{c}\text { Typical } \\
\text { Gamma Heating }_{\text {W/g (SS) }}^{c}\end{array}$ \\
\hline \multicolumn{5}{|l|}{ Northwest and } \\
\hline Northeast Flux Trap & $13.3 / 5.250$ & $4.4 \times 10^{14}$ & $2.2 \times 10^{14}$ & \\
\hline Other Flux Traps & $7.62 / 3.000^{d}$ & $4.4 \times 10^{14}$ & $9.7 \times 10^{13}$ & \\
\hline \multicolumn{5}{|l|}{ A-Positions } \\
\hline$(A-1-A-8)$ & 1.59 & $1.9 \times 10^{14}$ & $1.7 \times 10^{14}$ & 8.8 \\
\hline$(A-9-A-16)$ & $1.59 / 0.625$ & $2.0 \times 10^{14}$ & $2.3 \times 10^{14}$ & \\
\hline \multicolumn{5}{|l|}{ B-Positions } \\
\hline (B-1 - B-8) & $2.22 / 0.875$ & $2.5 \times 10^{14}$ & $8.1 \times 10^{13}$ & 6.4 \\
\hline$(\mathrm{B}-9-\mathrm{B}-12)$ & $3.81 / 1.500$ & $1.1 \times 10^{14}$ & $1.6 \times 10^{13}$ & 5.5 \\
\hline H-Positions (14) & $1.59 / 0.625$ & $1.9 \times 10^{14}$ & $1.7 \times 10^{14}$ & 8.4 \\
\hline \multicolumn{5}{|l|}{ I-Positions } \\
\hline Large (4) & $12.7 / 5.000$ & $1.7 \times 10^{13}$ & $1.3 \times 10^{12}$ & 0.66 \\
\hline Medium (16) & $8.26 / 3.500$ & $3.4 \times 10^{13}$ & $1.3 \times 10^{12}$ & \\
\hline Small (4) & $3.81 / 1.500$ & $8.4 \times 10^{13}$ & $3.2 \times 10^{12}$ & \\
\hline \multicolumn{5}{|l|}{ Outer Tank Positions } \\
\hline $\mathrm{ON}-4$ & $\operatorname{Var}^{\mathrm{e}}$ & $4.3 \times 10^{12}$ & $1.2 \times 10^{11}$ & 0.15 \\
\hline ON-5 & $\operatorname{Var}^{\mathrm{e}}$ & $3.8 \times 10^{12}$ & $1.1 \times 10^{11}$ & 0.18 \\
\hline ON-9 & $\operatorname{Var}^{\mathrm{e}}$ & $1.7 \times 10^{12}$ & $3.9 \times 10^{10}$ & 0.07 \\
\hline OS-5 & $\operatorname{Var}^{\mathrm{e}}$ & $3.5 \times 10^{12}$ & $1.0 \times 10^{11}$ & 0.14 \\
\hline OS-7 & $\operatorname{Var}^{\mathrm{e}}$ & $3.2 \times 10^{12}$ & $1.1 \times 10^{11}$ & 0.11 \\
\hline OS-10 & $\operatorname{Var}^{\mathrm{e}}$ & $1.3 \times 10^{12}$ & $3.4 \times 10^{10}$ & 0.05 \\
\hline OS-15 & $\operatorname{Var}^{\mathrm{e}}$ & $5.5 \times 10^{11}$ & $1.2 \times 10^{10}$ & 0.20 \\
\hline OS-20 & $\operatorname{Var}^{\mathrm{e}}$ & $2.5 \times 10^{11}$ & $3.5 \times 10^{9}$ & 0.01 \\
\hline
\end{tabular}

\footnotetext{
a. Position diameter; capsule diameter must be smaller.

b. Average speed $2,200 \mathrm{~m} / \mathrm{s}$.

c. Depends on configuration

d. East and south flux traps each contain 7 guide tubes with inside diameters of $1.76 \mathrm{~cm}(0.694 \mathrm{in})$. The center flux trap holds the Irradiation Test Vehicle having 3 tubes, two with 1.73-cm (0.681-in) inside diameter and one with $2.24 \mathrm{~cm}(0.881$-in) inside diameter.

e. Variable; can be either $2.22,3.33$, or $7.62 \mathrm{~cm}(0.875,1.312$, or $3.000 \mathrm{in})$
}

\subsection{Flux Augmentation}

The ATR was commission with a rated power of $250 \mathrm{MW}$. That assumed a uniform power distribution in each of the 4 corner lobes and the central region of the reactor, also referred to as a "lobe" of $50 \mathrm{MW}$ each. Shortly after commissioning, reactor power was reduced for most testing to $110 \mathrm{MW}$. The fluxes shown in Table 15 are those typically available at that power. The fast flux available in the northwest (NW) lobe, where the GTL is planned to be located, is only about $20 \%$ of that needed to meet the fast flux requirement for GTL [1]. To reach the fast flux level of $1.0 \times 10^{15} \mathrm{n} / \mathrm{cm}^{2} / \mathrm{s}$, the lobe power would need to be increased from its nominal $18 \mathrm{MW}$ to well over $70 \mathrm{MW}$. Operating the reactor at that power for extended periods is not feasible. 
Therefore, it is necessary to provide booster fuel for flux augmentation. Also, the natural fast-tothermal flux ratio in the NW lobe shown in Table 15 is only 0.5 . Thermal neutron filtering will be required to achieve the required fast-to-thermal ratio of 15 or greater.

\subsection{Summary}

The ATR was originally commissioned in 1967 with the primary mission of materials and fuels testing for the United States Naval Reactors Program. It is the highest power research reactor operating in the United States. Its large test volumes make it attractive for irradiations of materials and components. The ATR is designed to evaluate the effects of intense radiation on material samples, especially nuclear fuels. The principal customer for the reactor over most of its lifetime has been the U.S. DOE Naval Reactors Program. Other uses include isotope production for medical, industrial, environmental, agricultural and research applications. Irradiation services are provided for government programs as well as private firms and consortiums.

\subsection{CONCLUSIONS}

Here we consider the various merits and concerns for the facilities considered in light of the requirements of the T\&FR for the Gas Test Loop and programmatic concerns.

\subsection{Joyo}

The Japanese fast reactor Joyo provides many irradiation positions throughout the core that can be used for fuel and material irradiation testing. The technology and instrumentation in the irradiation rigs provided by Joyo are well advanced and can offer fairly accurate real-time irradiation data. However, it appears that it would take at least two irradiation rigs to provide the irradiation tests needed to meet the AFCI and GEN IV goals. Irradiation tests using several irradiation rigs could be time consuming, resulting in higher costs to perform the tests. Although recent efforts and core upgrades have increased the accessibility to customers, the availability of Joyo appears to be limited. Currently, most of its irradiation facilities are fully booked until 2010 and it is unclear what the availability of the irradiation facilities will be in the future, especially to foreign customers. Delays in testing and increased costs are also associated with the use of a foreign irradiation facility due to the licensing and transportation of radioactive materials.

\subsection{BOR-60}

The Russian BOR-60 reactor has proven itself as a reliable irradiation testing facility since 1969 and has conducted many successful irradiation campaigns that have been used to develop new technology and fuels for fast reactors. It provides a fast flux $\left(\mathrm{E}_{\mathrm{n}}>0.1 \mathrm{MeV}\right)$ greater than $10^{15}$ $\mathrm{n} / \mathrm{cm}^{2} / \mathrm{s}$ and is capable of producing high damage rates similar to the ones that could be achievable in the ATR Gas Test Loop. However, instrumentation for real-time data collection during irradiation testing appears to be limited. Online monitoring during irradiation testing is critical to meet the AFCI and GEN IV goals as well as testing for space nuclear power applications. The availability of BOR-60 to foreign customers is also in question and since it is a foreign irradiation facility, delays and increased cost for irradiation campaigns are predicted.

\subsection{HFIR}

The HFIR operated by ORNL in Tennessee is the one of the most powerful thermal research reactors in the world and is used for production of medical isotopes, neutron scattering 
experiments, and fuel and material irradiation testing. Although it has a peak fast flux $\left(\mathrm{E}_{\mathrm{n}}>0.1\right.$ $\mathrm{MeV}$ ) of $1.2 \times 10^{15} \mathrm{n} / \mathrm{cm}^{2} / \mathrm{s}$, it also has a peak thermal flux of $2.4 \times 10^{15} \mathrm{n} / \mathrm{cm}^{2} / \mathrm{s}$, resulting in a fast to thermal flux ratio less than 1. Customers extensively use the single flux trap located in the center of the core and it appears that it will not be available to produce the extended irradiation campaigns needed by AFCI and GEN IV. The production of medical isotopes in the HFIR is one of its primary missions and it is unclear whether HFIR would sacrifice the production of the isotopes to comply with the extended irradiation campaigns needed if the GTL were installed there.

\subsection{MTS}

When completed, the MTS will be one of the most powerful accelerator driven system in the world and will have the capability of producing testing environments similar to the ones found in liquid metal, sodium, and gas fast reactors. The MTS facility is being designed to be used specifically for fuel and material irradiation testing and will have an availability to customers that could be as high as $95 \%$. However, significant upgrades to LANSCE will need to be performed to achieve a fast flux $\left(\mathrm{E}_{\mathrm{n}}>0.1 \mathrm{MeV}\right)$ of $1.0 \times 10^{15} \mathrm{n} / \mathrm{cm}^{2} / \mathrm{s}$ or more.

The T\&FR for the GTL [1] calls for a minimum experimental volume diameter of $2.5 \mathrm{~cm}$ ( 1 inch), which is greater than the $1.5 \mathrm{~cm}$ planned for the MTS. The required specimen length capability in the T\&FR is $15.5 \mathrm{~cm}$. MTS is presently showing $12 \mathrm{~cm}$. The neutron energy fast-tothermal ratio is superb in MTS because there are essentially no thermal neutrons. However, the T\&FR calls for uniformity of $20 \%$ in neutron flux intensity over the specimen volume. The steep flux gradients in MTS are far from meeting this requirement. Additionally, just as the thermal tail in neutron energy would be atypical of the fast reactor spectrum in a thermal fission reactor, the super-energetic tail of the MTS will be atypical of the fast reactor spectrum.

An upgrade in the classification of the facility housing the MTS to a Category 3 nuclear facility will probably be required for testing of reactor fuels there.

\subsection{Advanced Test Reactor}

The large flux traps in the ATR have a potential test volume $12.7 \mathrm{~cm}(5 \mathrm{in})$ in diameter and $1.2 \mathrm{~m}$ (48 in) in length. With booster fuel assemblies and a double wall pressure boundary, the available diameter is still more than $7.6 \mathrm{~cm}$ ( 3 in) in diameter. The unperturbed fast $(\mathrm{E}>0.1$ $\mathrm{MeV}$ ) neutron flux in the test chamber is greater than $1.0 \times 10^{15} \mathrm{n} / \mathrm{cm}^{2} / \mathrm{s}$. The fast-to-thermal neutron flux ratio is greater than 15 for all configurations considered and greater than 25 for the more promising ones.

The ATR was constructed from the outset as a facility in which irradiation testing of fuels and materials could be carried out. The infrastructure to accommodate such testing is already in place. Demonstrated reactor availability is better than 270 operating days per year.

\subsection{Summary}

Of the irradiation facilities examined here, only the ATR will accommodate a test sample that meets the T\&FR requirements of a diameter of $2.54 \mathrm{~cm}$ and a length of $15.5 \mathrm{~cm}$. It has the most uniform neutron flux intensity over the test volume. Each of the five major candidate facilities has its own advantages for performing irradiation tests, but it appears that none of them alone 
can meet AFCI and GEN IV objectives. In order to meet the testing requirements of the U.S. nuclear programs, significant modifications would be required for each of the irradiation facilities. It is expected that the user would be responsible for much of the cost of upgrading a facility. Capital invested in foreign irradiation facilities would not guarantee access to the facility. While proof-of-principle testing of fast reactor fuels will need to be conducted in a fast reactor, there is a need for extensive testing of candidate materials before proof-of-principle testing can begin. An investment in the Department of Energy's own facilities to develop new testing capabilities will insure advanced reactor programmatic goals are met on time and are achieved in a cost effective manner.

For these reasons and others, the ATR is recommended as the best choice of facility in which to house the Gas Test Loop. 


\section{REFERENCES}

1. G. R. Longhurst, S. T. Khericha, and J. L. Jones, "Gas Test Loop Functional and Technical Requirements," INL/EXT-04-02273, Idaho National Engineering and Environmental Laboratory, September 2004.

2. "Experimental Fast Reactor Joyo", Japan Nuclear Cycle Development Institute, www.jnc.go.jp/zooarai/joyo/indexes.htm, accessed August 2004.

3. Experimental Fast Reactor Joyo, Brochure from the Japan Nuclear Cycle Development Institute, 4-49, Muramatsu, Tokai-mura, Naka-gun, Ibaraki, Japan 319-1194.

4. Ryskamp, John, Chris Grandy, Ron King, Irina Glagolenko, "Fast Irradiation Test Reactor Annual Report for FY 2004”, INEEL/INT-04-02256, September, 2004.

5. Fast Reactor Data Base, IAEA, Nuclear Power and Technology Development Section, IAEA-TECDOC-866, 1996.

6. Tabuchi, Shiro., Takafumi Aoyam, "Neutron Fluence Database of Experimental Fast Reactor Joyo for Fuel and Structural Material Irradiation Tests", Japan Nuclear Cycle Development Institute, Transactions, SMiRT 16, Washington DC, August 2001, www.ipmnet.ncsu.edu/C1796.PDF, accessed September 2004.

7. "Experimental Fast Reactor BOR-60", State Scientific Center of Russian Federation Research Institute of Atomic Reactors, Reactor Physics and Safety Department, www.niiar.ru/ofibr/en/e_ofibr.htm, Accessed August 2004.

8. "Pre- and In-pile Tests of Fuel Element Mock-ups for the BREST-OD-300 in the Independent Lead Cooled Channel of the BOR-60 Reactor", $11^{\text {th }}$ International Conference on Nuclear Engineering, Tokyo, Japan, 2003, ICONEII-36409, www.nikiet.ru/eng/publications/icone-11/ICONE11-36409.pdf.

9. “HFIR", Oak Ridge National Laboratory, Research Reactors Division, www.ornl.gov/sci/rrd/, accessed September 2004.

10. Nuclear Research Reactors in the World, IAEA, www.iaea.org/worldatom/rrdb.

11. "AFCI Material Test Station Overview”, Presentation by Michael W. Cappiello, Los Alamos National Laboratory, at the AFCI Semi-Annual Review, February 17, 2005, Alexandria, VA.

12. Gordon Wilcutt, October 2002, Part 2: Power and Peak Power Densities for Four Target Options, LA-UR-03-8956, Los Alamos National Laboratory.

13. Michael Cappiello, Los Alamos National Laboratory, personal communication, October 2004.

14. J. F. Briesmeister, Ed., March 2000, MCNP - A General Monte Carlo N-Particle Transport Code, LA-13079-M, Los Alamos National Laboratory, Los Alamos, New Mexico. 


\section{APPENDIX A: PRELIMINARY FACILITY INVESTIGATION}

Preliminary facility investigations were conducted on possible candidates as alternatives to the gas test loop. These facilities were evaluated primarily on fast flux capability and the fast-tothermal flux ratio. If a facility looked as if it could meet these requirements, it was selected for further research. Requirements not included in the preliminary site investigations were the following:

- Flux uniformity

- Peak fuel temperature

- Peak fuel temperature controllability

- Surrounding gas temperature

- Loop gas pressure

- Pressure controllability

- Atmospheric compatibility

- Gas flow to test chamber

- Instrumentation

- Temperature

- Pressure

- Gas composition

- Radioassay

- Data access

Facilities considered in this preliminary investigation are summarized in Table A.1.

Table A.1 Potential candidate facilities considered in preliminary investigation.

\begin{tabular}{|c|c|c|c|c|c|c|c|c|}
\hline \multirow{3}{*}{ Country } & \multirow{3}{*}{ Reactor } & \multirow{3}{*}{ Type } & \multirow{2}{*}{$\begin{array}{l}\text { Fast Flux }\left(\mathrm{n} / \mathrm{cm}^{2} / \mathrm{s},\right. \\
\qquad>0.1 \mathrm{MeV})\end{array}$} & \multirow{3}{*}{$\begin{array}{l}\text { Thermal } \\
\text { Flux }\end{array}$} & \multirow{3}{*}{$\begin{array}{c}\text { Fast To } \\
\begin{array}{c}\text { Thermal Flux } \\
\text { Ratio }\end{array} \\
\text { Required: }>15\end{array}$} & \multirow{3}{*}{\begin{tabular}{|c|}
$\begin{array}{c}\text { Damage } \\
\text { Rate }\end{array}$ \\
$>15$ \\
dpa/year \\
\end{tabular}} & \multicolumn{2}{|c|}{ Test Volume $(\mathrm{cm})$} \\
\hline & & & & & & & Diameter & Length \\
\hline & & & Required: $1.0 \mathrm{E}+15$ & & & & $2.54 \mathrm{~cm}$ & $15.5 \mathrm{~cm}$ \\
\hline \multirow{13}{*}{ USA } & HFIR & Tank & $1.0 \mathrm{E}+15$ & $2.4 \mathrm{E}+15$ & 0.5 & & 12.7 & 50 \\
\hline & ACRR & TRIGA & $4.0 \mathrm{E}+13$ & $4.0 \mathrm{E}+12$ & 10.00 & & & \\
\hline & FNR & Pool & $1.5 E+13$ & $1.5 \mathrm{E}+15$ & 0.01 & & & \\
\hline & GSTR & TRIGA & $2.5 E+13$ & $2.8 \mathrm{E}+13$ & 0.89 & & & \\
\hline & MITR-II & Tank & $1.7 \mathrm{E}+14$ & $7.0 \mathrm{E}+13$ & 2.43 & & 4.5 & 50 \\
\hline & MURR & Tank in Pool & $1.0 \mathrm{E}+14$ & $6.0 \mathrm{E}+14$ & 0.17 & & & \\
\hline & NBSR & Heavy Water & $2.0 \mathrm{E}+14$ & $4.0 \mathrm{E}+14$ & 0.50 & & & \\
\hline & OSTR & TRIGA & $1.0 \mathrm{E}+13$ & $1.0 \mathrm{E}+13$ & 1.00 & & & \\
\hline & PSBR & TRIGA & $3.0 \mathrm{E}+13$ & $3.3 E+13$ & 0.91 & & & \\
\hline & RINSC & Pool & $3.0 \mathrm{E}+13$ & $2.0 \mathrm{E}+13$ & 1.50 & & & \\
\hline & UT TRIGA II & TRIGA & $4.8 \mathrm{E}+13$ & $2.7 \mathrm{E}+13$ & 1.78 & & & \\
\hline & UWNR & TRIGA & $3.0 \mathrm{E}+13$ & $3.2 E+13$ & 0.94 & & & \\
\hline & MTS & ADS & $7.2 \mathrm{E}+14$ & - & - & $7.5-9.5$ & $1.5-2.0$ & 10 \\
\hline Russia & BOR-60 & Fast & $3.5 \mathrm{E}+15$ & - & - & 25 & $0.94-4.4$ & $45-100$ \\
\hline
\end{tabular}




\begin{tabular}{|c|c|c|c|c|c|c|c|c|}
\hline \multirow{12}{*}{ Country } & \multirow{3}{*}{ Reactor } & \multirow{3}{*}{ Type } & \multirow{3}{*}{\begin{tabular}{|c|}
$\begin{array}{c}\text { Fast Flux }\left(\mathrm{n} / \mathrm{cm}^{2} / \mathrm{s},\right. \\
\mathrm{E}>0.1 \mathrm{MeV})\end{array}$ \\
Required: $1.0 \mathrm{E}+15$ \\
\end{tabular}} & \multirow{3}{*}{$\begin{array}{l}\text { Thermal } \\
\text { Flux }\end{array}$} & \multirow{3}{*}{$\begin{array}{c}\text { Fast To } \\
\begin{array}{c}\text { Thermal Flux } \\
\text { Ratio }\end{array} \\
\text { Required: }>15\end{array}$} & \multirow{3}{*}{\begin{tabular}{|c|}
$\begin{array}{c}\text { Damage } \\
\text { Rate }\end{array}$ \\
\cline { 2 - 2 }$>15$ \\
dpa/year
\end{tabular}} & \multicolumn{2}{|c|}{ Test Volume $(\mathrm{cm})$} \\
\hline & & & & & & & Diameter & Length \\
\hline & & & & & & & $2.54 \mathrm{~cm}$ & $15.5 \mathrm{~cm}$ \\
\hline & BR-10 & Loop & $8.6 \mathrm{E}+14$ & $8.6 \mathrm{E}+14$ & 1.00 & & & \\
\hline & IBR-2 & Fast Burst & $1.5 \mathrm{E}+14$ & $1.7 \mathrm{E}+13$ & 8.82 & & & \\
\hline & IVV-2M & Pool & $1.5 \mathrm{E}+14$ & $5.0 \mathrm{E}+14$ & 0.30 & & & \\
\hline & MIR.M1 & Pool & $3.0 \mathrm{E}+14$ & $5.0 \mathrm{E}+14$ & 0.60 & & & \\
\hline & SM & Press. Vessel & $2.0 \mathrm{E}+15$ & $5.0 \mathrm{E}+15$ & 0.40 & & & \\
\hline & VK-50 & BWR Prototype & $1.5 \mathrm{E}+14$ & $5.0 \mathrm{E}+13$ & 3.00 & & & \\
\hline & WWR-M & Tank & $1.5 \mathrm{E}+14$ & $4.0 \mathrm{E}+14$ & 0.38 & & & \\
\hline & WWR-TS & Tank & $3.3 E+14$ & $1.8 \mathrm{E}+14$ & 1.83 & & & \\
\hline & BN-600 & Fast & $6.5 \mathrm{E}+15$ & - & - & & & \\
\hline \multirow{7}{*}{ Japan } & HTTR & High Temp Gas & $2.0 \mathrm{E}+13$ & $7.5 \mathrm{E}+13$ & 0.27 & & & \\
\hline & JMTR & Tank & $4.0 \mathrm{E}+14$ & $4.0 \mathrm{E}+14$ & 1.00 & & & \\
\hline & JOYO & Fast & $4.0 \mathrm{E}+15$ & $3.0 \mathrm{E}+11^{*}$ & $>999$ & & & \\
\hline & JRR-3M & Pool & $1.4 \mathrm{E}+14$ & $2.7 E+14$ & 0.52 & & & \\
\hline & JRR-4 & Pool & 8.7E+13 & $7.0 \mathrm{E}+13$ & 1.24 & & & \\
\hline & KUR & Tank & $6.5 \mathrm{E}+13$ & $6.0 \mathrm{E}+13$ & 1.08 & & & \\
\hline & Monju & Fast & $6.0 \mathrm{E}+15$ & - & - & & & \\
\hline \multirow{2}{*}{ France } & ORPHEE & Pool & $3.0 \mathrm{E}+14$ & $3.0 \mathrm{E}+14$ & 1.00 & & & \\
\hline & PHENIX & Fast & $7.2 \mathrm{E}+15$ & - & - & 36 & 4 & 85 \\
\hline Korea & HANARO & Pool & $4.5 \mathrm{E}+14$ & $3.0 \mathrm{E}+14$ & 1.50 & & & \\
\hline India & FBTR & Fast & $3.3 \mathrm{E}+15$ & - & - & & & 53.2 \\
\hline Netherlands & HFR & Tank in Pool & $4.6 \mathrm{E}+14$ & $2.7 \mathrm{E}+14$ & 1.70 & 7 & 7 & 58 \\
\hline Belgium & BR-2 & Tank & $8.4 \mathrm{E}+14$ & $1.2 \mathrm{E}+15$ & 0.70 & & 8.4 & 20 \\
\hline
\end{tabular}

* Thermal neutron flux in MARICO 


\section{APPENDIX B. IRRADIATION RIGS FOR JOYO}

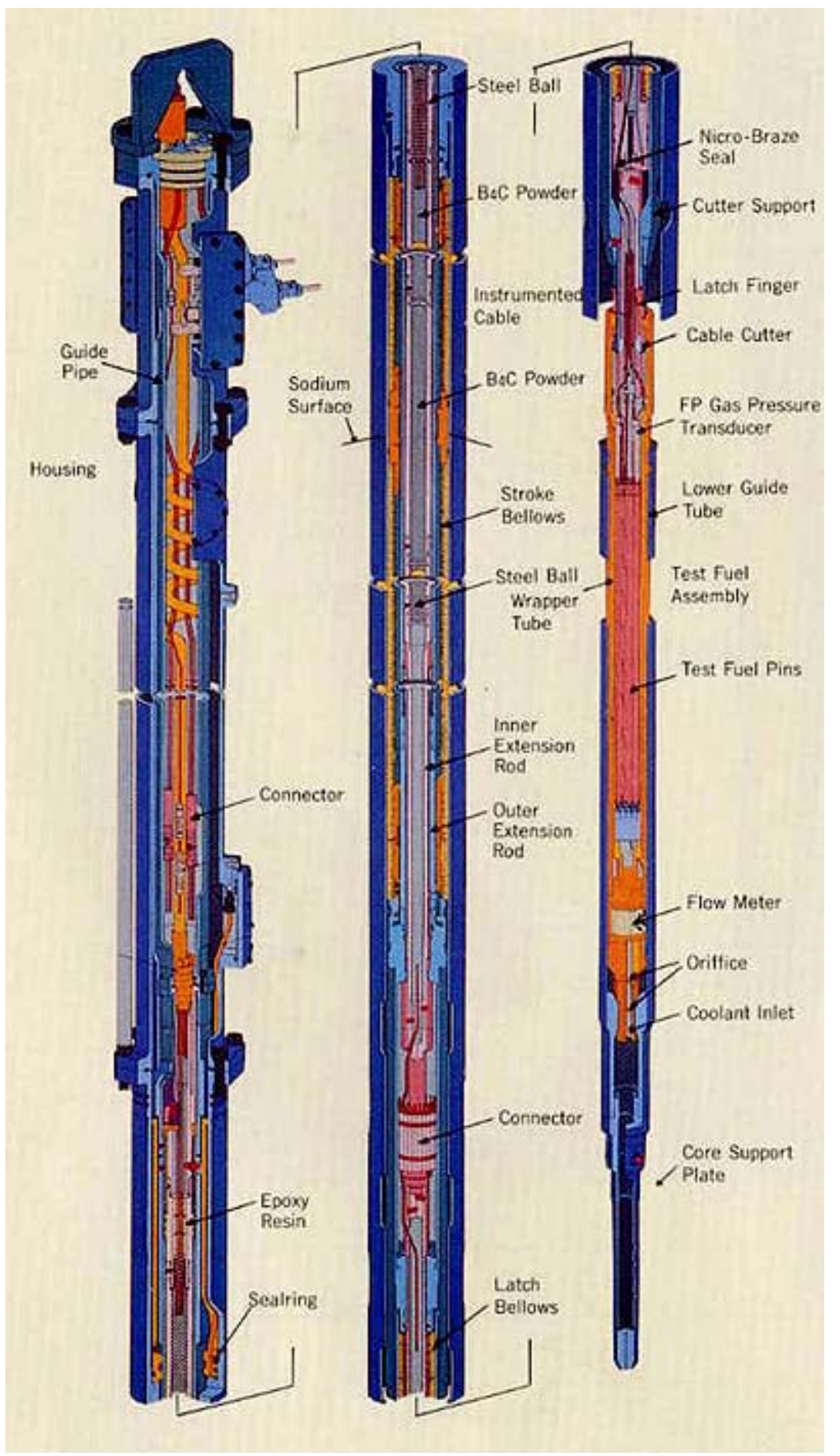

Figure B.1. Instrumented Test Assembly (INTA) [B-1]. 


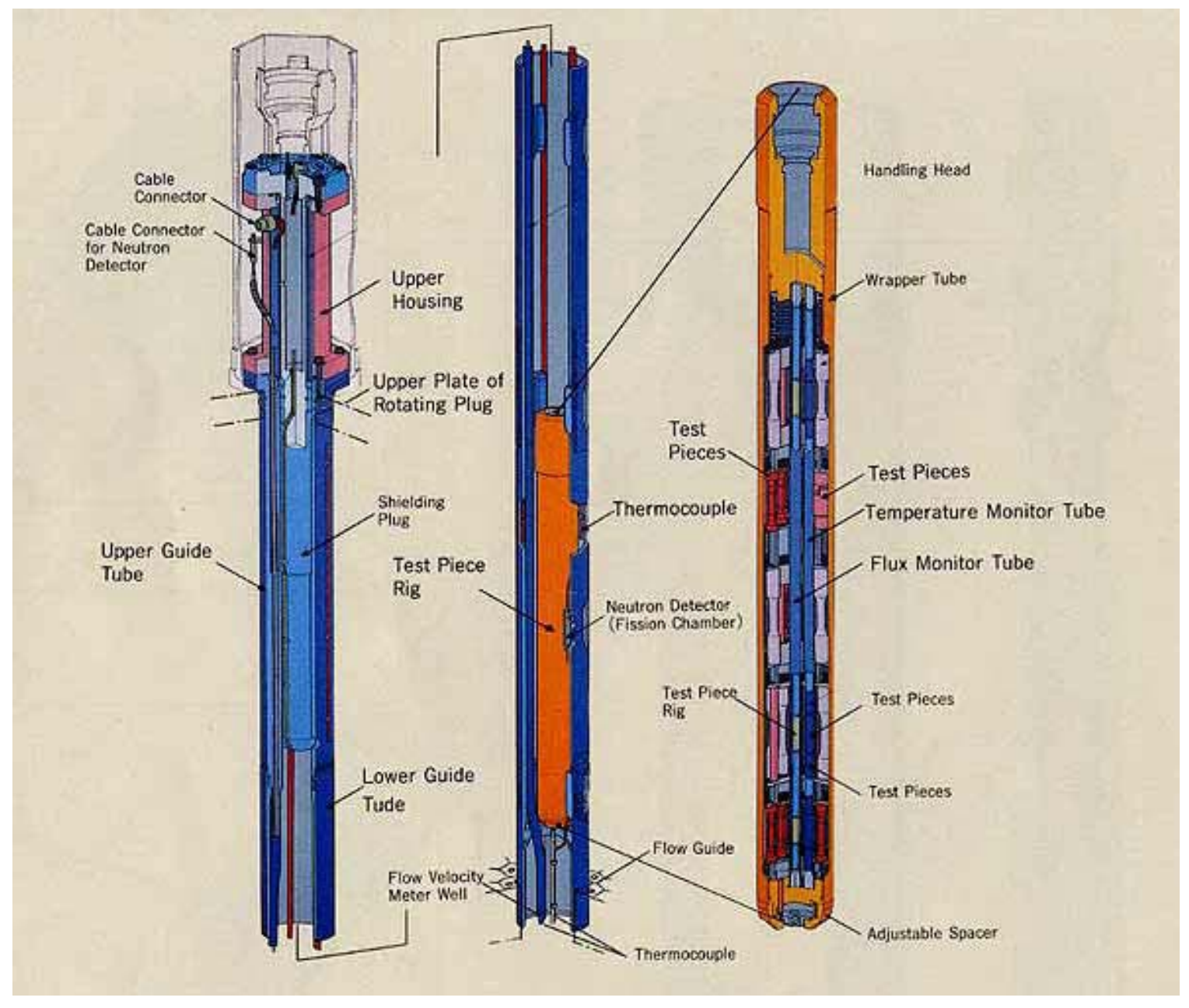

Figure B.2. Upper Core Structure Irradiation Plug Rig (UPR) [B-1]. 


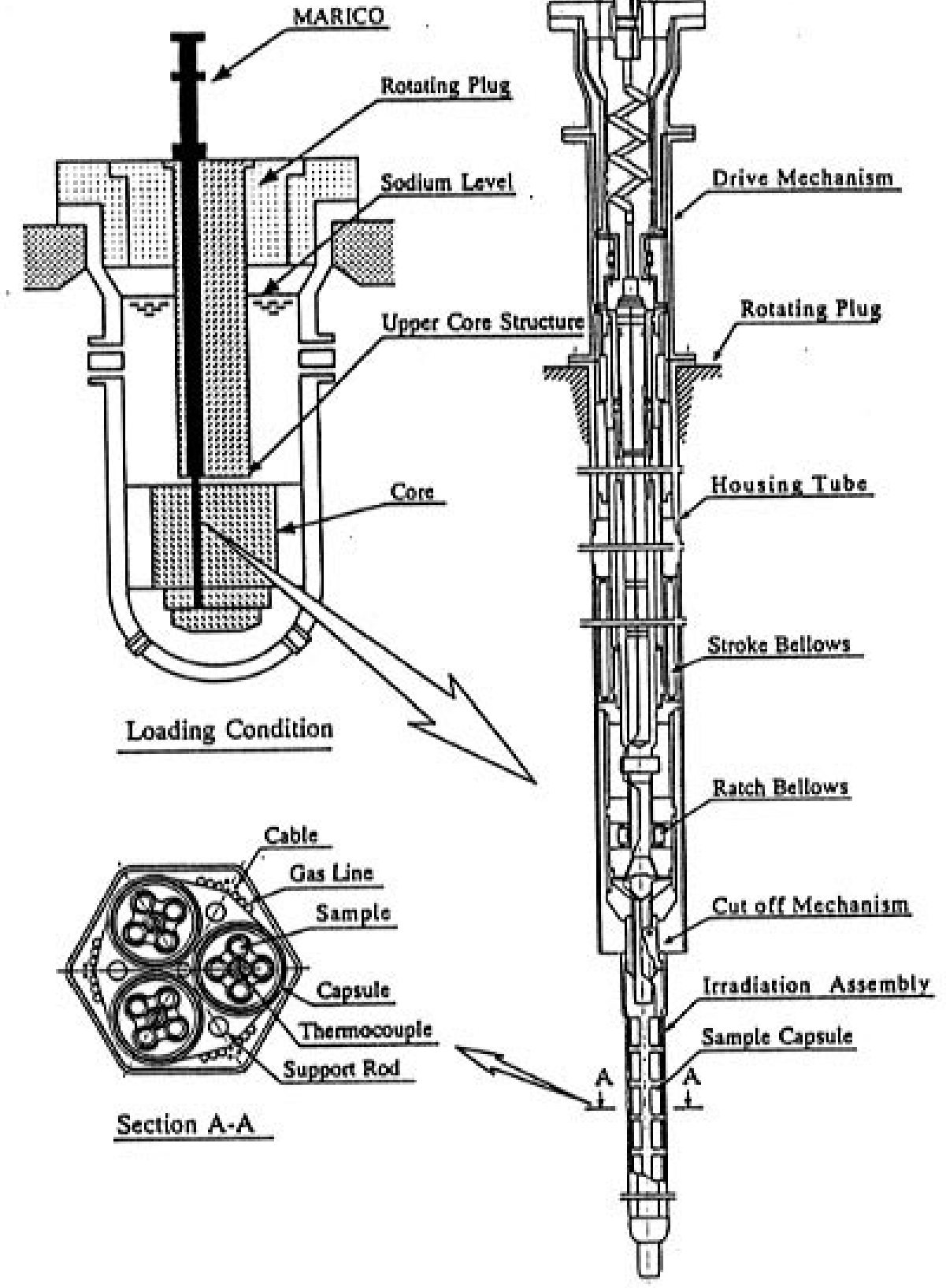

Figure B.3. Materials Testing Rig With Temperature Control [B-2]. 


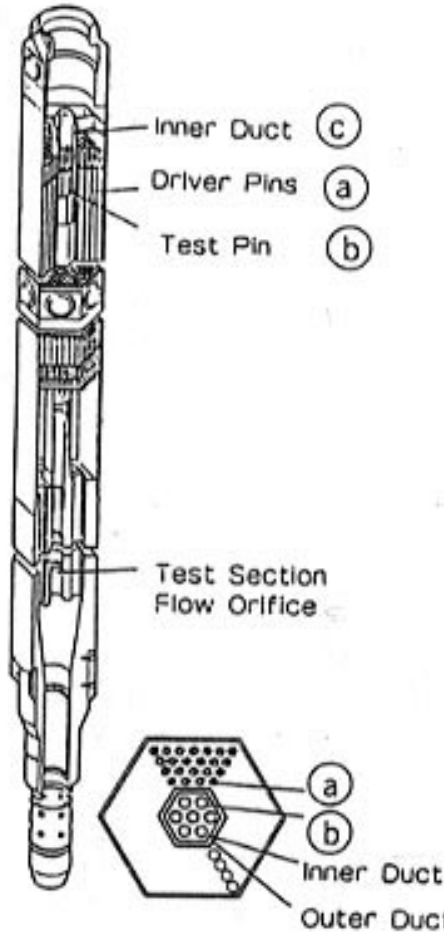

(UNIS-A)

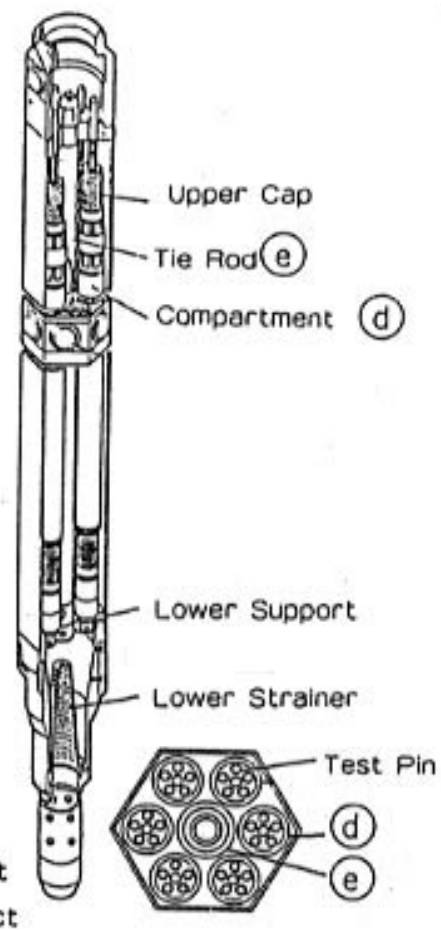

(UNIS-B)

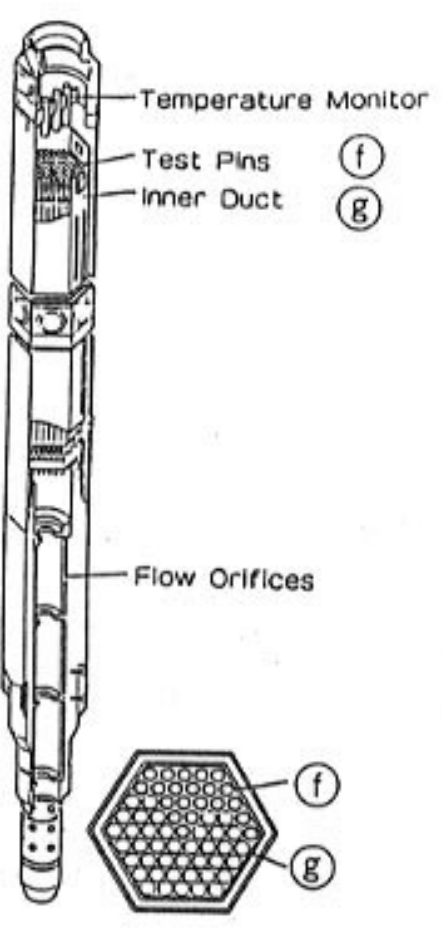

(UNIS-C)

Figure B.4. Uninstrumented Test Assemblies (UNIS) A, B, C [B-2].

\section{APPENDIX B REFERENCES}

B-1. Tabuchi, Shiro., Takafumi Aoyam, "Neutron Fluence Database of Experimental Fast Reactor Joyo for Fuel and Structural Material Irradiation Tests", Japan Nuclear Cycle Development Institute, Transactions, SMiRT 16, Washington DC, August 2001, www.ipmnet.ncsu.edu/C1796.PDF, accessed September 2004.

B-2. Fast Reactor Data Base, IAEA, Nuclear Power and Technology Development Section, IAEA-TECDOC-866, 1996. 